\title{
Bargaining with Commitment between Workers and Large Firms
}

\author{
William B. Hawkins* \\ University of Rochester
}

This version: February 10, 2011

First version: March 2010

\begin{abstract}
I study bargaining between workers and large firms when commitment to long-term contracts is feasible. The marginal surplus associated with a match is split in a pre-determined ratio, analogously to generalized Nash bargaining. Commitment avoids the over-hiring inefficiency identified by Stole and Zwiebel $(1996 a, b)$ and Smith (1999). However, even under the Hosios (1990) condition, the equilibrium is still not constrained efficient since large firms search too intensively relative to small firms. If workers can direct their search to firms by size, or if firms can hire workers instantaneously at constant marginal cost, the equilibrium is constrained efficient if the Hosios condition applies. The pattern of growth rates of firms by size can be used to identify how firms bargain with workers.
\end{abstract}

JEL Codes: E24, J31, J64.

Key words: bargaining, random search, multi-worker firms, efficiency

\footnotetext{
*Addresses: Harkness 232, Department of Economics, University of Rochester, Box 270156, Rochester, NY 146270156; william.hawkins@rochester.edu. An earlier version of this paper had the title 'Privately Efficient Bargaining between Workers and Large Firms.' I thank Mark Bils, Manolis Galenianos, Leo Kaas, Philipp Kircher, Rafael Lopes de Melo, Giuseppe Moscarini, Eric Smith, and seminar participants at Rochester, the Richmond Fed, Yale, and the Search and Matching Conference at the University of Essex for very helpful comments. The usual disclaimer applies.
} 


\section{Introduction}

There has been increasing recent interest in using models with matching frictions in the labor market to account for the dynamics of firm and establishment growth. A class of familiar stylized facts, for example, that large firms pay higher wages (Brown and Medoff, 1989; Davis and Haltiwanger, 1991), or that younger and faster-growing firms pay higher wages (Brown and Medoff, 2003), have been recently augmented by new information on the pattern of vacancy posting and of hiring per vacancy across firms from new data sources such as the Job Opening and Labor Turnover Survey for the United States (Davis, Faberman and Haltiwanger, 2010). In addition, models in which large firms employ multiple workers in a frictional labor market have found use in studying regulation, trade, and technological change.

Mechanisms of wage determination and firm behavior in such an environment have, however, been under-studied. Accordingly, in this paper I study a bargaining model of a labor market in which firms wish to employ multiple workers. The production technology operated by firms exhibits decreasing returns to labor. Matching is frictional, so that workers are employed by the firm sequentially, and so that firms and workers cannot sign contracts before they have undergone a costly matching process. However, once a worker has been matched with an employer, the two are able to commit jointly to a long-term contract governing future wage payments and employment continuation. This is the key innovation of this paper relative to the previous benchmark modeling framework in this literature, due to Stole and Zwiebel (1996a,b), Smith (1999), and Cahuc and Wasmer (2001), where firms and workers were assumed unable to commit to any form of long-term contract. ${ }^{1}$ The marginal surplus associated with a new match is divided between the firm and the new employee in a predetermined ratio, analogously to generalized Nash bargaining. I characterize equilibrium in this economy, including employment, unemployment, and wage payments to workers.

The main focus of the paper is on studying the efficiency of equilibrium. It is possible for the equilibrium allocation in this environment to be constrained efficient, but, perhaps surprisingly, the familiar Hosios (1990) condition does not by itself suffice for this. The reason is that when search is random and firms are heterogeneous (which they are in the model if hiring is time-consuming, so that firms differ in size and in the marginal product of labor), then the Hosios condition does not suffice to make low marginal-product firms internalize the congestion externality associated with their vacancy-posting activity. If the bargaining power of a worker is independent of the size of the firm she negotiates with, then firms of different sizes and productivities will not face the correct incentive to hire additional workers. Firms with a high marginal product of labor face too low an incentive to hire, so that they post too few vacancies and grow too slowly; firms with a low marginal product of labor earn too high a return from hiring an additional worker, so that they post too many vacancies and grow too fast. This inefficiency vanishes only if the value function of firms is linear in the relevant range for employment, which occurs only if either there are constant returns to labor in production, or constant returns in the vacancy-posting technology. Alternatively,

\footnotetext{
${ }^{1}$ Stole and Zwiebel (1996a) termed their assumption 'extreme employment-at-will' (p. 377).
} 
efficiency obtains if the bargaining power of workers varies with a firm's marginal product in a very specific manner (workers' bargaining power must be higher when they negotiate with large firms), or if workers can condition their search on the size of the firm and the Hosios condition applies. This last assumption brings an element of directed search to the environment I study, and clarifies exactly why constrained efficiency obtains in the directed search model of Kaas and Kircher (2010), developed contemporaneously with the current paper.

I then use a calibrated version of the model to study quantitatively how large is the welfare cost of the inefficiency I identify. It turns out to be of the same order of magnitude as the over-hiring inefficiency arising in models of bargaining without commitment (Stole and Zwiebel, 1996a,b; Smith, 1999; Cahuc and Wasmer, 2001), at least when the decreasing returns to labor in production are not too severe. In a calibration modeled on Shimer's (2005) calibration of the Mortensen-Pissarides model in which decreasing returns arise from managerial span-of-control concerns (Lucas, 1978), the welfare cost of the inefficiency I identify is 0.7 percentage points of steady-state consumption, relative to the constrained efficient allocation, even when the Hosios condition holds. (Bargaining without commitment induces a welfare cost of 2.3 percentage points.)

The value of comparing equilibrium allocations with their constrained efficient counterparts is to understand the effect of policy interventions on welfare. Constrained efficiency can be restored in equilibrium in my model in the presence of an appropriate tax and transfer scheme that corrects the inefficiencies arising from bargaining. However, for a benevolent planner to be able to impose the correct Pigouvian tax requires that the planner be able to identify the structure of the economy, and in particular, whether the economy is already constrained efficient, and whether bargaining between firms and workers proceeds under commitment, as in my model, or in its absence, as in the model of Stole and Zwiebel (1996a,b) and Smith (1999). When firms grow slowly, these economies can be distinguished from each other by the pattern of firm growth. A companion paper, Hawkins (2011) shows that identifying the nature of bargaining is even more difficult in the case of constant returns in the vacancy-posting technology: in that case, data on firm profitability is required for identification.

I commence the paper by presenting the economic environment in Section 2. In Section 3 I introduce my model of bargaining, and discuss its implications for wage dynamics (which are of course not unique in a model with full commitment), and in Section 4 I characterize and prove the existence of equilibrium. I discuss conditions under which equilibrium allocations are constrained efficient in Section 5. Section 6 and Section 7 study the case in which the bargaining power of workers does not vary with firm size in more detail, first theoretically and then in a calibrated model. The remainder of the paper is devoted to understanding better where the constrained efficiency result arises from. I draw a contrast with directed search models in Section 8. In Section 9 I discuss the limiting case of the model in which hiring more workers can be done by the firm instantaneously and at a constant marginal cost per worker hired. In this case the Hosios condition suffices for constrained efficiency, but identification of the wage bargaining process is more difficult. I examine the role of the full commitment assumption (in Section 10) and place 
the paper in the context of the burgeoning literature on large firms operating in frictional labor markets concludes the paper (in Section 11). Section 12 concludes briefly.

\section{Benchmark Economic Environment}

In this section I introduce the underlying production and matching technologies that characterize the economic setting I study in my benchmark model. The setting studied here could be significantly generalized, for example, to allow for aggregate and idiosyncratic productivity shocks, as well as exogenous separations of workers from firms; however, none of these features would alter the main message of the paper. For the sake of simplicity I therefore do not incorporate them in my model.

Time is continuous. All agents are risk neutral and discount the future at rate $r$. There are two types of agents, workers and firms. There is a fixed measure 1 of workers, who can at any time be either unemployed (in which case they produce flow unemployment income $b$ ) or employed by some firm. The flow output of a firm employing $n \geq 0$ workers is given by $y(n)$; the production function $y$ is strictly increasing and strictly concave; I normalize $y(0)=0$ and assume that $y(n)-y(n-1)<b$ for $n$ sufficiently large so as to guarantee that firm size is finite in equilibrium. Employment $n$ can take any non-negative integer value.

There is a large measure of potential entrant firms. At any moment a potential entrant firm has the option of paying an entry cost $k>0$ and becoming active. An active firm, at any moment, has the option of posting arbitrarily many vacancies; posting $v$ vacancies requires payment of a flow cost of $c(v)$. I assume that $c(\cdot)$ is strictly increasing and strictly convex, and normalize $c(0)=0 .^{2}$ I also assume that $c(\cdot)$ satisfies the standard Inada conditions that $\lim _{v \rightarrow 0} c^{\prime}(v)=0$ and $\lim _{v \rightarrow \infty} c^{\prime}(v)=+\infty$.

A matching function $M(u, \bar{v})$ maps the measures of unemployed workers and the total measure of vacancies posted by firms to a flow rate at which these agents are matched in pairs. Each unemployed worker is matched to a randomly-chosen vacancy at Poisson rate $M(u, \bar{v}) / u$ and each vacancy is matched to a randomly-chosen unemployed worker at Poisson rate $M(u, \bar{v}) / \bar{v}$. I assume that $M(u, \bar{v})$ exhibits constant returns to scale in $(u, \bar{v})$. Define $\theta=\bar{v} / u$, the labor market tightness or vacancy-unemployment ratio. The assumption of constant returns to scale implies that the Poisson vacancy-filling rate and the Poisson job-finding rate for a worker can be written as functions

\footnotetext{
${ }^{2}$ Given that Davis, Faberman and Haltiwanger (2010) argue that patterns of vacancy posting across firms are consistent with increasing, rather than decreasing, returns to scale at the establishment level, it is perhaps necessary to justify the relevance of the assumption of decreasing returns here. Three types of defences can be offered. First, the argument of Davis, Faberman and Haltiwanger (2010) applies only if vacancies as measured in JOLTS data are a good proxy for the vacancies considered here, which should more properly be considered as a generalized measure of recruiting intensity. (What matters here is that doubling the Poisson rate of arrival of new hires should more than double the recruiting cost. This need not literally arise from decreasing returns in the technology for posting advertisements: for example, firms could advertise more intensively per vacancy, relax hiring standards, or screen workers less intensively.) Second, if there are indeed increasing returns to scale but only locally (for example, because there is a fixed cost of establishing a recruiting department within the firm), the inefficiency I focus on will still be present. Finally, in Section 9 I show that if the vacancy-posting technology as I model it exhibits even constant returns to scale, let alone increasing returns, then the dynamics of hiring at the firm level take a 'bang-bang' form, which would be inconsistent with patterns of time-consuming growth at the establishment level being caused by labor market frictions.
} 
of $\theta$ alone. Specifically, the rate at which a firm posting $v$ vacancies contacts a worker is $v q(\theta)=$ $v M(u, \bar{v}) / \bar{v}=v M\left(\theta^{-1}, 1\right)$, and the rate at which an unemployed worker receives a job offer is $f(\theta)=\theta q(\theta)=M(u, v) / u=M(1, \theta)$. I assume that $q$ is monotonically decreasing in $\theta$ and satisfies the Inada conditions $\lim _{\theta \rightarrow 0} q(\theta)=+\infty$ and $\lim _{\theta \rightarrow \infty} q(\theta)=0$. I also assume that $f$ is monotonically increasing in $\theta$ and satisfies $f(0)=0$ and $\lim _{\theta \rightarrow \infty} f(\theta)=\infty$. All these assumptions are satisfied if $M$ is Cobb-Douglas in $(u, v)$, as Petrongolo and Pissarides (2001) cannot reject in US data.

Existing firms are destroyed at a Poisson rate $\delta>0$; in this case all the existing workers return to unemployment, and the firm is destroyed; there is no scrapping value. I assume that firms and workers can voluntarily terminate any existing match at any time.

The unemployment rate is a state variable of the model; its law of motion is given by

$$
\dot{u}=\delta(1-u)-f(\theta) u
$$

In this paper I consider only steady-state allocations, so I will always impose the constraint that $\dot{u}=0$.

I assume that

$$
\max _{n} \frac{1}{n}[y(n)-(r+\delta) k]>b
$$

so that positive entry is efficient and occurs in equilibrium; if (2) fails then no firms enter and all workers remain unemployed forever.

This completes the description of the basic economic environment. To close the model requires specifying how wages are determined. This is the subject of the next section.

\section{Bargaining with Commitment}

In this section I outline a theory of how firms and workers bargain in an environment where commitment to binding long-term contracts is possible. As foreshadowed in the Introduction, I assume that, when a firm and a worker meet, they negotiate over a long-term, state-contingent contract which governs wages and the continuation of employment. I assume that the firm and the worker are able to negotiate a contract committing them to continue their employment relationship when it is jointly efficient to do so: that is, when the continuation value of the relationship exceeds the sum of the values of the firm's outside option, which is to continue with one fewer worker, and of the worker's outside option, unemployment. When matching occurs, the surplus associated with the match has to be divided between the firm and its workers somehow; I assume that this surplus is divided in a predetermined ratio.

Formalizing this notion is in general cumbersome, since writing the value of a firm requires keeping track of the various commitments it has made to its incumbent workforce regarding future wage payments. However, because of the assumption of full commitment to the contract governing the employment relationship by both the firm and the worker, the timing of wage payments within the employment relationship is indeterminate. It simplifies notation to assume that in continuing 
relationships, workers receive payments that make their value the same as if they returned to unemployment. ${ }^{3}$ I assume that any payment in excess of this amount that is due to the worker during an employment relationship is paid at the time of hiring as a lump-sum payment. This means that the only state variable for a firm is the number of incumbent employees, $n$. Under this assumption, denote by $J_{t}(n)$ the value of a firm in an ongoing relationship with $n$ incumbent employees at time $t$. Write $h_{t}(n-1)$ for the value of the payment due to a newly-hired worker at the conclusion of her negotiations with the firm with $n-1$ incumbent workers with which she has just been matched at time $t$, and $V_{t}^{u}$ for the value of an unemployed worker at time $t$. I assume that $h_{t}(n)$ is chosen to maximize a standard generalized Nash product,

$$
h_{t}(n)=\arg \max _{x}\left(J_{t}(n+1)-x-J_{t}(n)\right)^{1-\eta(n)} x^{\eta(n)}
$$

The first-order condition for this problem is necessary and sufficient, and can be rearranged to establish that

$$
h_{t}(n)=\eta(n)\left[J_{t}(n+1)-J_{t}(n)\right] .
$$

$\eta(n)$ is the bargaining power of a worker when negotiating with a firm with $n$ incumbent workers; $(\eta(0), \eta(1), \ldots)$ are structural parameters of the model. The benchmark case to consider is that $\eta(n) \equiv \eta$ is independent of $n$, but more generally I allow for a worker's bargaining power to depend on the size of the firm she is negotiating with.

The 'hiring bonus' payment $h_{t}(n)$ will be positive exactly when the surplus generated by forming the match, given by $\left[\left(x+V_{t}^{u}\right)-V_{t}^{u}\right]+\left[\left(J_{t}(n+1)-x-J_{t}(n)\right]=J_{t}(n+1)-J_{t}(n)\right.$, is positive. In this paper I abstract both from idiosyncratic and from aggregate shocks, so that it will therefore never be efficient to terminate an ongoing employment relationship. This is because no match associated with a negative surplus can arise when firms anticipate that wage payments in ongoing matches will be as described in this paragraph. ${ }^{4}$

I term the bargaining protocol introduced in this section bargaining with commitment. In summary, this amounts to the assumption that a worker who is newly-matched at time $t$ with a firm which had $n$ incumbent employees receives a payment $h_{t}(n)$ characterized by (4) immediately. Thereafter, the relationship continues until the firm is exogenously destroyed (recall that this occurs at Poisson rate $\delta$ ). Until this happens, at any date $t+\tau$, the worker receives a flow payment of $r V_{t+\tau}^{u}$.

In Section 10 below I discuss further the nature of contracting and the roles of the assumptions on the commitment power of firms and workers and on the timing of payments. I now proceed to characterizing equilibrium under bargaining with commitment.

\footnotetext{
${ }^{3}$ Of course, because workers have committed to the employment relationship, this indifference condition is purely formal. However, under this assumption on the timing of payments, the assumption that workers can commit is not binding. This contractual form is the same as what Shimer (1996) terms 'simple contracts.'

${ }^{4}$ More generally, in a stochastic environment, the payment timing specified above would not lead to any disagreement about when to terminate an ongoing employment relationship, so that separations would remain privately efficient.
} 


\section{Equilibrium}

I now return to the benchmark payment timing and define and characterize equilibrium under bargaining with commitment. I restrict to considering only steady state equilibria, so I do not index variables by time. In steady state, the Hamilton-Jacobi-Bellman equation for the value of a firm with $n$ employees takes the form

$$
(r+\delta) J(n)=y(n)-n r V^{u}-c(v(n))+q v(n)[J(n+1)-J(n)-h(n)] .
$$

The flow output of the firm is $y(n)$, of which $r V^{u}$ is paid to each incumbent employee and $c(v(n))$ is spent on posting vacancies to attract new workers. A new worker is contacted with Poisson rate proportional to the number of vacancies posted, as well as to the hiring rate per vacancy $q=q(\theta)$. When a worker is matched with the firm, employment is always agreed on (since bargaining is privately efficient and since the firm would not post vacancies were it not ex post efficient to consummate the hire), a lump-sum payment $h(n)$ is made to the new hire, and the firm experiences the capital gain $J(n+1)-J(n)$. Because of the assumption characterizing the sharing of surplus in $(4), h(n)=\eta(n)[J(n+1)-J(n)]$, so that (5) can be rewritten more simply as

$$
(r+\delta) J(n)=y(n)-n r V^{u}-c(v(n))+(1-\eta(n)) q v(n)[J(n+1)-J(n)] .
$$

$v(n)$ denotes the optimal vacancy posting policy of the firm, defined by

$$
v(n)=\arg \max _{v}\{-c(v)+q v(1-\eta(n))[J(n+1)-J(n)]\} .
$$

Since $c(\cdot)$ is strictly convex and satisfies Inada conditions, the solution for $v(n)$ is unique. If $J(n+1)-J(n)>0$, then $v(n)$ satisfies the necessary and sufficient first-order condition

$$
c^{\prime}(v(n))=q(1-\eta(n))[J(n+1)-J(n)]
$$

while if $J(n+1) \leq J(n)$, then $v(n)=0$.

The fact that any inactive firm can become active by paying the entry cost $k$ establishes that $J(0) \leq k$. Since I assumed in (2) that the economy is sufficiently productive, in fact this must hold with equality in steady state, so that in equilibrium,

$$
J(0)=k
$$

The HJB equation for an unemployed worker is

$$
r V^{u}=b+f(\theta) \frac{\sum_{n=0}^{\infty} g(n) v(n) h(n)}{\sum_{n=0}^{\infty} g(n) v(n)} .
$$

When a worker contacts a firm with $n$ incumbent employees, she receives a lump-sum payment $h(n)$. She contacts some firm at Poisson rate $f(\theta)$; the probability that the firm contacted has 
$n$ incumbent employees is proportional to the measure of such firms, $g(n)$, and to the measure of vacancies posted by each such firm, $v(n)$. Note that the assumption that search is random is embodied by the form of (10): the worker would like to meet a firm which pays a high signing bonus $h(n)$, but cannot do anything to influence the chance of this occurring. Instead, conditional on matching, she is randomly matched with an arbitrary vacancy drawn from the unconditional distribution of vacancies across firms.

Denote by $g(n)$ the measure of firms with employment level equal to $n$. The firm size distribution $g(n)$ evolves according to the simple differential equation (where the dot denotes the derivative with respect to time)

$$
\dot{g}(n)= \begin{cases}-(\delta+q v(0)) g(0)+e & n=0 \\ -(\delta+q v(n)) g(n)+q v(n-1) g(n-1) & n \geq 1\end{cases}
$$

Here $e$ denotes the flow measure of firms paying the entry cost $k$ and becoming active. The measure of firms with 0 employees increases with entry by newly-active firms, and decreases as incumbent firms with no employees are either exogenously destroyed or succeed in hiring a new employee. Firms with a positive number $n$ of employees increase in number as firms with $n-1$ employees succeed in hiring, and decrease in number as a result either of exogenous destruction or successful hiring by a firm with $n$ incumbent employees. In steady state, $\dot{g}(n)=0$ for all $n$, so that

$$
(\delta+q v(0)) g(0)=e
$$

and

$$
(\delta+q v(n)) g(n)=q v(n-1) g(n-1) .
$$

The unemployment rate also evolves according to (1); in steady state this implies that

$$
\delta(1-u)=f(\theta) u
$$

Market tightness must be consistent with the vacancy-posting policy of firms and with the measure of unemployed workers:

$$
\theta u=\sum_{n=0}^{\infty} g(n) v(n)
$$

This allows me to make the following definition of equilibrium.

Definition 4.1 (Steady-state Equilibrium). A steady-state equilibrium is a market tightness $\theta$, an unemployment rate $u$, an entry rate $e$, a firm size distribution $(g(0), g(1), \ldots)$, a vacancy-posting policy $(v(0), v(1), \ldots)$, a value of unemployment $V^{u}$, a sequence of values of firms $(J(0), J(1), \ldots)$, and a sequence of payments $(h(0), h(1), \ldots)$, such that

- $J(n)$ satisfies the HJB equation (6);

- $h(n)$ satisfies (4) for each $n$; 
- $v(n)$ satisfies (7) for each $n$;

- the free entry condition (9) holds;

- $V^{u}$ satisfies $(10)$;

- the evolution of the firm size distribution and of the unemployment rate follow (12), (13), and (14); and

- $\theta$ satisfies (15).

Establishing the existence of a steady-state equilibrium is straightforward. Conditional on the value of market tightness $\theta$ and of an unemployed worker $V^{u}$, the firm's HJB equations can be uniquely solved, and this solution implies a vacancy-posting policy $v(n)$. Using $v(n)$ and equations (12) and (13), I can solve for the firm size distribution. I then need to verify whether the guessed values for $\theta$ and $V^{u}$ are consistent with (9) and (10); this reduces the problem to a fixed-point problem which I can show has a solution (the details of this argument, along with other omitted proofs, are in the Appendix.)

Proposition 4.2 (Existence of Equilibrium under Bargaining with Commitment). A steady-state equilibrium under bargaining with commitment exists.

While in numerical examples, the equilibrium appears to be unique, the presence of two offsetting effects makes it difficult to prove uniqueness in theory. When the posited value of an unemployed worker $V^{u}$ is high, firms post relatively few vacancies, which makes jobs difficult to find and drives down the value of an unemployed worker given by the right side of (10); on the other hand, it means that the firm size distribution implied by (12) and (13) is more concentrated on firms with relatively low numbers of employees. Such firms pay higher hiring bonuses $h(n)$, all else equal, which increases the value of the right side of (10). These offsetting effects make it difficult to apply the kind of argument that proves the uniqueness of equilibrium in the benchmark MP model.

\section{Constrained Efficient Allocations}

Suppose that there is a benevolent planner for the economy; this planner takes as given the frictional matching process of the economy and the production technology, and subject to these constraints, attempts to maximize social welfare. Since all agents are risk-neutral, this is equivalent to maximizing the present discounted value of output. The planner's key choice variables are a vacancy-posting strategy for each active firm, and a time path for the flow rate at which potential firms become active in order to maximize the present discounted value of output. (The choices of these two variables then endogenously determine market tightness, the distribution of firms by size, and the unemployment rate.) This problem is in general high-dimensional, but characterization of the optimum is straightforward in steady state. This is because the planner optimally requires all firms 
with current employment $n>0$ to post the same number of vacancies, because the strictly concave production function $y(\cdot)$ and weakly convex vacancy-posting cost function are common to all firms. This reduces the planner's problem to a choice of sequences of the labor market tightness $\theta_{t}$, the unemployment rate $u_{t}$, the flow entry rates $e_{t}$ of new firms, measures $g_{t}(n)$ of incumbent firms with current employment $n$, and vacancy posting policies $v_{t}(n)$ for such firms. I will characterize optimal steady state allocations only, so I assume that in fact all these sequences are constant. The maximization problem for the planner then takes the form characterized as follows.

Definition 5.1 (Constrained Efficient Allocations). The constrained efficient allocation solves

$$
\max _{e, g(\cdot), v(\cdot), \theta, u} \int_{0}^{\infty} e^{-r t}\left[b u-e k+\sum_{n=0}^{\infty} g(n)[y(n)-c(v(n))]\right] d t
$$

subject to

$$
\begin{gathered}
0=\theta u-\sum_{n=0}^{\infty} g(n) v(n) \\
0=\dot{g}(n)= \begin{cases}-(\delta+q(\theta) v(n)) g(n)+q(\theta) v(n-1) g(n-1) & n \geq 1 \\
-(\delta+q(\theta) v(0)) g(0)+e & n=0\end{cases} \\
0=\dot{u}=-f(\theta) u+\delta \sum_{n=0}^{\infty} n g(n)
\end{gathered}
$$

Flow output is the sum of the income generated by unemployed workers and the output of firms, less entry costs and vacancy posting costs. Equation (17), the analog to the equilibrium condition (15), requires that labor market tightness $\theta$ be equal to the ratio of the measures of vacancies posted by firms and of unemployed workers. Equation (18) is the analog to the equilibrium condition (11) and requires that the evolution of the firm size distribution be consistent with the hiring and firm destruction process.

The characterization of efficient allocations in Definition 5.1 allows comparison with equilibrium allocations, using Definition 4.1 and Proposition 4.2. Consider any equilibrium allocation which involves positive vacancy posting by some firms; then $\theta>0$. In this case I can rewrite the constraint on an efficient allocation (17) in an equivalent form by multiplying by $q(\theta)$ to obtain

$$
0=f(\theta) u-q(\theta) \sum_{n=0}^{\infty} g(n) v(n)
$$

Denote by $\lambda(n)$ the multipliers on the constraint (18), by $\lambda^{u}$ the multiplier on (19), and by $\mu$ the multiplier on (20). Intuitively, I can interpret $\lambda^{u}$ as the shadow value to the planner of an unemployed worker, $\hat{\lambda}(n) \equiv \lambda(n)-n \lambda^{u}$ as the shadow marginal value of having $n$ employees matched to a single firm rather than being unemployed, and $\hat{\mu} \equiv \mu-\lambda^{u}$ as the shadow value of a new match. With this notation I can state the following result. 
Theorem 5.2 (Efficiency of Equilibrium). Steady-state equilibrium under bargaining with commitment is constrained efficient if and only if for each $n$,

$$
\eta(n)=\frac{\hat{\mu}}{\hat{\lambda}(n+1)-\hat{\lambda}(n)} .
$$

The proof of Theorem 5.2 given in the Appendix relies on manipulating the first-order conditions for a constrained efficient allocation to show that if an equilibrium allocation is efficient, then in fact $\hat{\lambda}(n)=J(n)$ for each $n$, and $\lambda^{u}=V^{u}$. That is, efficiency requires that the private value of a firm with $n$ employees is the same as the marginal increase in value it provides to the planner (relative to the alternative where the firm is destroyed and the $n$ employees returned to unemployment), and likewise that the private value of future income of an unemployed worker is the same as her marginal value to the planner. This can only be achieved if the value of the bargaining power $\eta(n)$ takes a specific value for each $n$. If the bargaining power of workers $\eta(n)$ is too high for some $n$, firms with $n$ incumbent workers have too little incentive to post vacancies and hire workers, while if $\eta(n)$ is too low, such firms post too many vacancies as they do not internalize the congestion externality they exert on other firms. In addition, if the bargaining power of workers is too high, entry is insufficient, while if it is too low, entry is excessive.

A somewhat mathematical intuition for why (21) gives the appropriate value for the bargaining power can be seen from the first-order conditions that characterize the values taken by $v(n)$, the measure of vacancy posting by firms with $n$ workers, in the efficient allocation and in the decentralized equilibrium. In the equilibrium, according to (8), vacancy posting satisfies

$$
c^{\prime}(v(n))=(1-\eta(n))[J(n+1)-J(n)],
$$

while in the efficient allocation, I show in the proof of Theorem 5.2 that

$$
c^{\prime}(v(n))=\hat{\lambda}(n+1)-\hat{\lambda}(n)-\hat{\mu} .
$$

Intuitively, the term on the right side of (22) is the private incentive of a firm to post vacancies, measured by the increase in value obtained by acquiring an $(n+1)$ st worker less the fraction $\eta(n)$ of this value which must be paid to that worker according to the assumed bargaining process. On the right side of (23), by contrast, is the marginal increase in the value for the planner when a firm with $n$ workers is matched with an additional worker, which arises from the value of a firm with $n+1$ workers less the value of a firm with $n$ workers and also less the value of a representative match. In order for the equilibrium to generate the efficient pattern of vacancy posting across firms, these values must coincide. However, if $\hat{\lambda}(n) \equiv J(n)$ and $\lambda^{u}=V^{u}$, so that the equilibrium values of firms and of unemployed workers are the same as their values to the planner, then the two conditions can coincide only if

$$
\hat{\lambda}(n+1)-\hat{\lambda}(n)-\hat{\mu}=(1-\eta(n))[J(n+1)-J(n)],
$$


which can be rearranged to give (21) under the assumption that $J(\cdot) \equiv \hat{\lambda}(\cdot)$. In a constrained efficient allocation, the shadow value of vacancy posting is equated across firms, taking into account the effect that more intense vacancy posting by one group of firms makes matching more difficult for other groups of firms through congestion. The marginal increase in congestion caused by a firm posting more vacancies, however, is independent of the particular firm that is posting vacancies: this can be seen mathematically in that the term $\hat{\mu}$ occurring in (23) and (24) does not vary with $n$. Vacancy posting in the equilibrium can only coincide with the constrained efficient allocation if the payment firms make to workers happens to equal $\hat{\mu}$, independently of $n$. Since the marginal surplus $J(n+1)-J(n)$ is decreasing in $n$ because of decreasing returns to labor, this can only happen if the bargaining power increases with $n$, and (26) gives the precise way in which this has to occur.

The discussion thus far has focused on the conditions required to generate efficient vacancy posting by firms of different sizes relative to each other. In fact efficiency requires more than this: it requires also that the average level of vacancy posting across firms, and not just the relative vacancy posting of different firms, be efficient. In the benchmark MP model, the Hosios condition that the bargaining power equal the elasticity of the matching function is required for this. The following Corollary to Theorem 5.2 establishes that, in an appropriately-defined average sense, bargaining power must also satisfy the Hosios condition in order to ensure efficient entry also in the multi-worker environment studied in this paper.

Corollary 5.3 (Hosios Condition). If the equilibrium is constrained efficient, then

$$
\frac{\sum_{n=0}^{\infty} g(n) v(n)}{\sum_{n=0}^{\infty} \frac{g(n) v(n)}{\eta(n)}}=-\frac{\theta q^{\prime}(\theta)}{q(\theta)}
$$

The intuition for this result is the same as in the single-worker case of the benchmark MP model. When firms wish to hire a single worker, if the average level of bargaining power is appropriate, the private cost to a firm of hiring (that is, the payments it must make to the hired worker) exactly equals the congestion externality its vacancy-posting imposes on other firms, so that it effectively internalizes the externality and decides to post vacancies only to the extent that this is efficient. Here, if (21) held but the value of $\hat{\mu}$ was, for example, too low, then each firm would realize too high a private benefit from vacancy-posting and would impose a congestion externality on other firms. (21) would ensure that it was not especially large firms, or especially small firms, that were imposing an excessive congestion externality on other firms, but that all firms were equally doing so. In order to ensure constrained efficiency, the level of $\hat{\mu}$ therefore needs to be determined appropriately. The condition for this, according to Corollary 5.3, is exactly that the Hosios condition hold in the appropriate average sense. More precisely, (25) shows that the elasticity of $q(\theta)$ with respect to $\theta$ must equal a weighted harmonic mean of the bargaining powers $\eta(n)$, weighted by the measures of vacancies posted by firms with $n$ incumbent employees, which is $g(n) v(n)$. It should already be clear from the previous discussion that the converse to Corollary 5.3 is not true in general: even if the bargaining power of firms is correct in an average sense, it still need not be true that the 
relative intensity of vacancy posting by firms of different sizes is what the planner would like it to be. Note that $-\theta q^{\prime}(\theta) / q(\theta)=u / M(u, v) \times \frac{\partial}{\partial u} M(u, v)$ is just the elasticity of the matching function with respect to unemployment, as usual.

The Hosios (1990) condition can be criticized since there is no reason to expect that the bargaining power, which is a structural parameter of how firms and workers split a bilateral surplus, should equal the elasticity of the matching function, which is a completely unrelated object. ${ }^{5}$ To summarize the results of this section thus far, in the environment I study, this criticism is doubly powerful. Not only does a Hosios-type condition need to hold on average for the equilibrium allocation to be constrained efficient, but the bargaining power needs to vary with firm size, and that in a way that is characterized by (21). Moreover, the terms appearing in that equation, namely the multipliers $\hat{\lambda}(n)$ and $\hat{\mu}$, depend not only on the matching function, but also on the production function, the vacancy posting cost function, and other parameters of the model in a complicated way. For example, the first-order condition for the optimal steady-state value of $g(n)$ can be rewritten as

$$
(r+\delta) \hat{\lambda}(n)=y(n)-n r \lambda^{u}-c(v(n))+q v(n)[\hat{\lambda}(n+1)-\hat{\lambda}(n)-\hat{\mu}] ;
$$

so that the production function $y(\cdot)$, the vacancy-posting cost function $v(n)$, and other primitives of the model enter into the equations defining the terms occurring on the right side of (21). Therefore the required set of bargaining power parameters $(\eta(0), \eta(1), \ldots)$ would need to be different across economies which differed in any model primitive. (For the derivation of (26), refer to the proof of Theorem 5.2.) Moreover, even within a given economy, a worker's bargaining power would need to be greater the larger the firm he was bargaining with, which seems less plausible than the reverse assumption. Thus, that (21) holds may be regarded by some readers as somewhat implausible. Therefore I now proceed in the next section to study the special case in which workers' bargaining power is independent of the size of the firm.

\section{Constant Bargaining Power}

In this Section I study bargaining with commitment when workers' bargaining power is a constant. In addition to the plausibility reasons given in the previous paragraph for considering this case, the assumption of constant bargaining power is also the usual benchmark imposed by authors studying bargaining without commitment. ${ }^{6}$ It is therefore interesting to investigate this case also when studying bargaining with commitment. I first show that equilibrium is inefficient in this environment except in trivial cases. This should not be surprising in view of Theorem 5.2. I then show that the inefficiency manifests itself in the pattern of vacancy-posting across firms.

\footnotetext{
${ }^{5}$ Of course, in an environment where search is directed and not random, the Hosios condition is necessarily satisfied since the competitive posting of contracts by market-makers generates an equilibrium relationship between the two quantities (Moen, 1997; Shimer, 1996). This carries over to this environment (Kaas and Kircher, 2010).

${ }^{6}$ Examples of papers studying bargaining without commitment and assuming that the bargaining power of workers is independent of firm size include Stole and Zwiebel (1996a,b), Smith (1999), Cahuc and Wasmer (2001), and Acemoglu and Hawkins (2010), for example.
} 
Unproductive (large) firms post too many vacancies, and the largest firms are inefficiently large.

First, it is immediate from Theorem 5.2 that equilibrium will be inefficient in this case unless $\hat{\lambda}(n+1)-\hat{\lambda}(n)$ is independent of $n$. However, intuitively, $\hat{\lambda}(\cdot)$ inherits the strict concavity of the production function, so that when firms hire more than one worker, this cannot happen. The following Proposition formalizes this result

Proposition 6.1 (Inefficiency of Equilibrium under Constant Bargaining Power). Suppose that $\eta(n) \equiv \eta$ for all $n$.

- Any steady-state equilibrium in which $v(1)>0$ is constrained inefficient.

- Any steady-state equilibrium in which $v(1)=0$ is constrained efficient if and only if $\eta=$ $-\frac{\theta q^{\prime}(\theta)}{q(\theta)}$ and $\hat{\lambda}(2)-\hat{\lambda}(1)-\hat{\mu}<0$.

That is, any efficient equilibrium in which bargaining power does not vary with the employment level of the firm is trivial, in the sense that no firms ever hire more than a single worker. In this case the model is essentially identical to the MP model, so it is unsurprising that the Hosios (1990) condition is sufficient to guarantee efficiency. (It must be noted that the condition that bargaining power is constant in employment if firms only ever hire a single worker isn't exactly difficult to satisfy!)

How does the inefficiency show up in an economy in which worker's bargaining power is constant and equal to the Hosios value $-\theta q^{\prime}(\theta) / q(\theta)$ ? Intuitively, the Hosios condition guarantees that entry is efficient conditional on the behavior of firms after entry. However, the fact that bargaining power is independent of $n$ means that firms with a high marginal value of hiring (that is, where $J(n+1)-J(n)$ is large) have to pay too large a payment to any worker they hire (since $h(n)$ is proportional to $J(n+1)-J(n)$ when $\eta(n) \equiv \eta$ is constant). On the other hand, firms with a low marginal value of hiring, where $J(n+1)-J(n)$ is small, have to pay too little. Therefore, small firms (which are the firms with high marginal product of labor in this model) have too low an incentive to post vacancies and therefore grow inefficiently slowly; on the other hand, large firms (with low marginal product) have too much incentive to post vacancies, so both grow inefficiently quickly, and also over-hire.

To formalize the over-hiring result, I first consider the behavior of firms in partial equilibrium. That is, I assume that firms whose vacancy posting is constrained efficient and firms who bargain with commitment with workers with constant bargaining power both take as given the same values of the matching rate per vacancy, $q(\theta)$, and of the flow value of an unemployed worker, $V^{u}$; I then ask how their patterns of vacancy posting differ. More precisely, given the primitives of the model such as the production, matching, and vacancy-posting cost functions, I first calculate the constrained efficient allocation, and evaluate market tightness and the value of an unemployed worker in that environment. I then take the same primitive economic environment, and ask how a single firm that took $q(\theta)$ and $V^{u}$ as given would behave, if it either negotiated with its workers according to bargaining with commitment. This is the subject of the following Proposition. 
Proposition 6.2 (Over-hiring in Partial Equilibrium). In partial equilibrium, the maximum firm size $n_{C}^{*}$ under bargaining with commitment is greater than the maximum firm size $n_{C E}^{*}$ in the constrained efficient allocation.

Proposition 6.2 is an over-hiring result. It establishes that even under bargaining with commitment, and independent of the value of the bargaining power of workers, the fact that large firms do not have to pay workers high enough wages in order to internalize the congestion externality that their vacancy posting causes leads them to over-hire workers. The reason for over-hiring is entirely separate from the familiar over-hiring identified by Stole and Zwiebel (1996a,b), Smith (1999), and Cahuc and Wasmer (2001), which arises in the case of bargaining without commitment when firms hire additional workers in order to drive down the wages of all incumbent workers. Here, the over-hiring arises because firms do not internalize the congestion externality they cause. This economic force is actually also present in the case of bargaining without commitment: the familiar over-hiring result in that setting is actually more complex than previously realized. ${ }^{7}$

The result of Proposition 6.2 is stated in partial equilibrium, keeping the market tightness and the value of an unemployed worker unchanged. Of course, if all firms in the economy bargain with commitment and constant bargaining power, these two variables are endogenous. In general equilibrium, the over-hiring result continues to hold, however: in fact, intuitively it is strengthened because in an inefficient allocation, the flow value of an unemployed worker falls, driving down wages and increasing hiring further.

Proposition 6.3 (Over-hiring in General Equilibrium). In general equilibrium, the maximum firm size $n_{C}^{*}$ under bargaining with commitment is greater than the maximum firm size $n_{C E}^{*}$ in the constrained efficient allocation.

Finally, note that a planner able to use appropriate tax and transfer instruments would be able to restore efficiency in this environment. This is the subject of the following Proposition.

Proposition 6.4 (Efficiency of Equilibrium with Taxes). Suppose that $\eta(n) \equiv \eta$ for all $n$. Suppose that the planner imposes a lump-sum tax on firms for each worker hired, or alternatively a flow tax per worker employed, and rebates the revenue to workers. Then, if the tax is appropriately chosen, the equilibrium is constrained efficient. If $\eta=0$ then the required tax is independent of the employment of the firm.

The reason that constrained efficiency is not obtained in the absence of taxes and transfers is that the intensity of vacancy-posting of firms of different sizes will not be efficient; in addition, if the Hosios condition does not hold in the appropriate average sense, entry will not be efficient conditional on vacancy-posting. This can be rectified if the planner imposes a lump-sum tax on a firm with $n$ incumbent workers so that it pays $\hat{\mu}-\eta(\hat{\lambda}(n+1)-\hat{\lambda}(n))$ in order to hire an

\footnotetext{
${ }^{7}$ Proposition 6.2 can be extended to show that a firm which bargains with workers under lack of commitment, as formalized in Acemoglu and Hawkins (2010), over-hires by more, in the sense that the maximum firm size under bargaining without commitment, $n_{N C}^{*}$, is greater than $n_{C}^{*}$. I give a proof in the Appendix as part of the proof of Proposition 6.2.
} 
$(n+1)$ st employee. The $\hat{\mu}$ component of the tax forces the firm to internalize the externalities its posting of vacancies imposes on other firms. The remaining component makes the firm the full remaining residual claimant on the surplus generated by its hiring of a new worker. (In fact, since $\hat{\lambda}(n+1)>\hat{\lambda}(n)$ for firms which post vacancies, this component is a subsidy: it compensates the firm for rent extracted by workers.) With this choice of tax scheme, firms' private incentives for both vacancy-posting and entry coincide with the social marginal values of these activities, so that the allocation generated by the equilibrium with taxes and transfers is constrained efficient. The proof of Proposition 6.4 is obvious from this discussion, so is omitted.

\section{Calibrated Model}

In the previous section, I showed that the equilibrium where firms have constant bargaining power is not constrained efficient even when the Hosios condition is satisfied. In this section I ask, in a calibrated model, whether the resulting inefficiency is significant. I find that it is economically nontrivial, and depending on the parameters of the economy (in particular, on the degree of decreasing returns to labor in production), may be of the same order of magnitude as the over-hiring resulting from lack of commitment.

Calibrating the model requires taking a position on the source of decreasing returns to labor at the firm level. Decreasing returns could arise from many types of quasi-fixed factors. If physical capital is more difficult to adjust than labor, then leaving it unchanged while the firm hires more workers gives rise to decreasing returns. More generally, organizational capital and marketing and supplier relationships also provide possible sources of decreasing returns, as might scarce managerial talent (Lucas, 1978). Finally, a firm producing a differentiated product might also experience a decreasing marginal revenue product of labor arising from a downward-sloping demand curve for its good. I do not wish to take a position on the source of decreasing returns, and therefore consider two relatively extreme possibilities, by assuming that the production function is Cobb-Douglas, $y(n)=A n^{\alpha}$, with $\alpha$ equal either to 0.667 , a standard choice in macro models which could be justified here by assuming that capital is completely fixed, and $\alpha=0.95$, more consistent with managerial talent being the fixed factor.

I solve the model numerically in a variant in which employment at the firm level is a continuous variable rather than taking on only integer values. ${ }^{8}$ This ensures that integer problems do not lead to misleading comparative statics. In addition to reporting results for the constrained efficient allocation and for the case of bargaining with commitment, I also calculate results for bargaining without commitment. The model of bargaining without commitment is exactly as set out in Acemoglu and Hawkins (2010), and has the familiar feature that in addition to the over-hiring induced by constant bargaining power, as highlighted in the current paper, firms additionally have an incentive to hire workers beyond the point where their marginal product equals their flow outside

\footnotetext{
${ }^{8}$ The accompanying note provides a more complete specification of the continuous-employment version of the model.
} 


\begin{tabular}{|c|c|c|c|}
\hline Variable & $\begin{array}{l}\text { Fixed } \\
\text { capital }\end{array}$ & $\begin{array}{l}\text { Span of } \\
\text { control }\end{array}$ & Explanation \\
\hline$r$ & \multicolumn{2}{|c|}{0.01} & Period is quarterly \\
\hline$\delta$ & \multicolumn{2}{|c|}{0.1} & Unemployment inflow rate \\
\hline$A$ & 4.52 & 1.29 & $\begin{array}{l}\text { Maximum establishment size } 23.8 \\
\text { in constrained efficient allocation }\end{array}$ \\
\hline$\alpha$ & 0.667 & 0.95 & Fixed capital \\
\hline$b$ & \multicolumn{2}{|c|}{0.4} & Normalization \\
\hline$\psi$ & \multicolumn{2}{|c|}{0.72} & Matching function $q(\theta)=Z \theta^{-\psi}$ \\
\hline & \multirow{2}{*}{\multicolumn{2}{|c|}{1.39}} & Shimer (2005); slope of Beveridge curve \\
\hline$Z$ & & & Unemployment rate of $6.87 \%$ \\
\hline$\phi$ & \multicolumn{2}{|c|}{1} & Vacancy cost $c(v)=\gamma v^{1+\phi} /(1+\phi)$ \\
\hline$\gamma$ & 0.0193 & 0.143 & $40 \%$ of unemployed value from $b$ \\
\hline$\eta$ & \multicolumn{2}{|c|}{0.72} & Hosios condition \\
\hline$k$ & 109.5 & 8.715 & Vacancy yield $q(\theta)=1.5$ \\
\hline
\end{tabular}

Table 1: Parameterization

option in order to drive down the wage of incumbent workers. ${ }^{9}$

Much of the calibration is relatively standard; I follow Shimer (2005) to the extent possible to aid comparability with the literature. I set the period of time to be quarterly, and set the interest rate $r=0.01$. I choose $\delta=0.1$ to match the unemployment inflow rate (since all employment to unemployment transitions in the model arise from exogenous firm destruction. I set the matching function as Cobb-Douglas, $M(U, V)=Z U^{\psi} V^{1-\psi}$, and set $\psi=0.72$ to be consistent with the slope of the Beveridge curve as in Shimer (2005). In models of bargaining, I then set the (constant) bargaining power of workers to be $\eta=0.72$ so that the Hosios condition holds. The target for the steady-state value of $\theta$ and the value of the parameter $Z$ are chosen to match a target a job-finding rate for workers of 1.355 as in Shimer (2005) and a job-filling rate for firms of 1.5, consistent with an average vacancy duration of around two months (van Ours and Ridder, 1992). This requires $Z=1.39$ and $\theta=0.903$. In the context of the constrained efficient allocation, I target a maximum establishment size of 23.8, following the evidence on average U.S. firm size from Davis et al. (2006), and I also normalize the flow value of an unemployed worker, $r V^{u}$, to 1 ; this requires setting the scale parameter in the Cobb-Douglas production function to $A=4.52$ when $\alpha=0.667$, and to $A=1.29$ when $\alpha=0.95$. (Firm sizes will be larger and the value of an unemployed worker lower under an inefficient equilibrium with bargaining.) In the absence of much guidance from the literature, I choose a quadratic vacancy-posting cost function, $c(v)=\gamma v^{2}$, and then select the value of $\gamma$ so that so that 40 percent of the flow value of an unemployed worker arises from home production and 60 percent from the expected capital gain of finding a job. This requires setting $\gamma=0.0193$ when $\alpha=0.667$, and $\gamma=0.143$ when $\alpha=0.95$. (Since I targeted $r V^{u}=1$, this calibration strategy also

\footnotetext{
${ }^{9}$ As noted in footnote 7 and in the proof of Proposition 6.2 in the Appendix, it can be shown theoretically that over-hiring is more severe in the case of bargaining without commitment than in the case of bargaining with commitment and constant bargaining power. This is consistent with the results presented in Table 2.
} 


\begin{tabular}{cccc}
\hline & Efficient & Commitment & No commitment \\
\hline \multicolumn{4}{c}{ Fixed capital $(\alpha=0.667)$} \\
\hline$\theta$ & 0.903 & 0.903 & 0.903 \\
$r V^{u}$ & 1 & 1 & 1 \\
$n^{*}$ & 23.8 & 27.4 & 62.5 \\
$v(0)$ & 35.33 & 35.26 & 28.5 \\
$v(20)$ & 3.3 & 5.4 & 13.3 \\
\hline \multicolumn{4}{c}{ Span of control $(\alpha=0.95)$} \\
\hline$\theta$ & 0.903 & 0.903 \\
$r V^{u}$ & 1 & 1 & 0.903 \\
$n^{*}$ & 23.8 & 61.6 & 1 \\
$v(0)$ & 3.66 & 3.47 & 2.96 .3 \\
$v(20)$ & 0.36 & 1.29 & 1.77 \\
\hline
\end{tabular}

Table 2: Partial equilibrium comparisons

implies that $b=0.4$.) Intuitively, $\gamma$ is identified because the expected capital gain associated with job-finding increases in the vacancy-posting cost, which measures the extent of frictional matching rents that are shared with workers under bargaining. Finally, I choose the free-entry cost $k$ to be consistent with zero profits for firms in the constrained efficient allocation. This aids in making the equilibrium allocations more comparable with the constrained efficient allocation. When $\alpha=0.667$, I therefore set $k=109.5$, while when $\alpha=0.95$, I set $k=8.715$. The parameterization is summarized in Table 1.

Table 2 reports partial equilibrium comparisons of key endogenous variables, and Figure 1 provides a graphical representation of value functions, vacancy-posting by firms, and the firm size distribution. More precisely, I solve for the constrained efficient allocation given the parameterization in Table 2, then, taking value of market tightness $\theta$ and the value of unemployment $V^{u}$ from this economy, characterize the behavior of a single firm that bargained with workers either according to bargaining with commitment as studied in this paper, or according to bargaining without commitment as in Acemoglu and Hawkins (2010). (Accordingly, the free-entry condition will not hold for such a firm.) Table 2 shows that this single firm over-hires, as predicted by Proposition 6.2, and the more so if it bargains without commitment. Over-hiring is greater the less concave the production function: if decreasing returns to scale are more severe, the fact that additional workers are very unproductive limits the firm's incentives to hire them. Figure 1 shows that under both parameterizations, vacancy-posting is greatest for new entrant firms in the constrained efficient allocation, less for bargaining with commitment, and less again for bargaining without commitment. However, vacancy-posting falls much more quickly with firm size in the constrained efficient allocation, a manifestation of the over-hiring phenomenon. In the constrained efficient allocation, firms grow more quickly when small but stop their growth path earlier, as can be seen from the bottom two panels of Figure 1. 

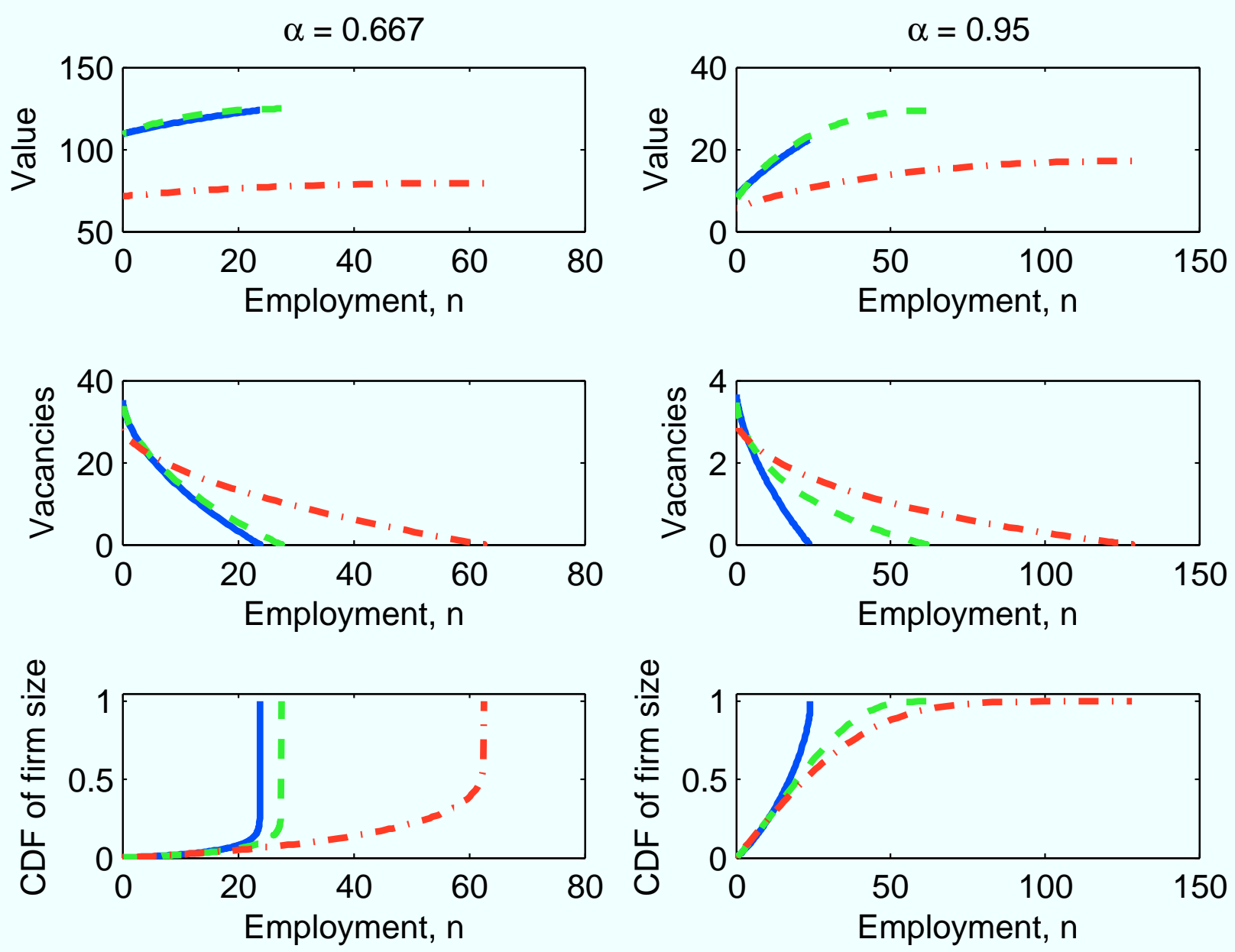

Figure 1: Partial equilibrium. The left three subfigures show results for the parameterization with $\alpha=0.667$, the right three for $\alpha=0.95$. In each case, the top figure shows firm's value functions, the center figure shows vacancy-posting, and the bottom figure shows the CDF of the firm size distribution. In each case, the blue solid curve shows the constrained efficient allocation, the green dashed curve shows bargaining with commitment, and the red dotted curve bargaining without commitment. 


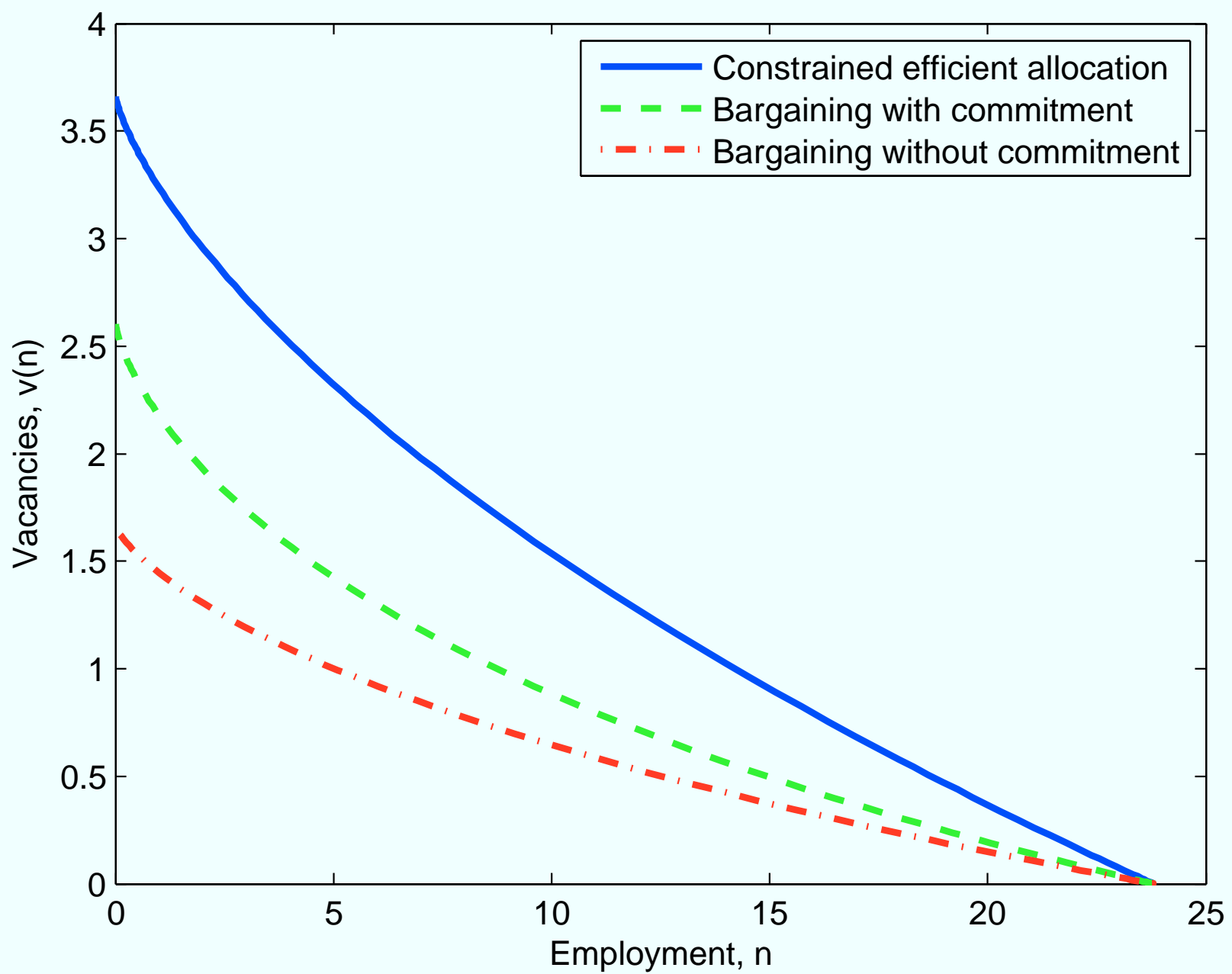

Figure 2: Identification from the pattern of vacancy-posting. 


\begin{tabular}{cccc}
\hline & Efficient & Commitment & No commitment \\
\hline \multicolumn{3}{c}{ Fixed capital } \\
\hline$\theta$ & 0.903 & 0.923 & 0.572 \\
$r V^{u}$ & 1 & 0.997 & 0.803 \\
$n^{*}$ & 23.8 & 27.7 & 120.9 \\
$v(0)$ & 35.3 & 35.3 & 35.3 \\
$v(20)$ & 3.3 & 5.6 & 22.3 \\
\hline \multicolumn{3}{c}{ Span of control } \\
\hline$\theta$ & 0.903 & 0.846 & 0.662 \\
$r V^{u}$ & 1 & 0.993 & 0.977 \\
$n^{*}$ & 23.8 & 70.8 & 204.1 \\
$v(0)$ & 3.66 & 3.66 & 3.66 \\
$v(20)$ & 0.36 & 1.50 & 2.54 \\
\hline
\end{tabular}

Table 3: General equilibrium comparisons.

An alternative way of understanding the difference in the pattern of vacancy-posting across firms is shown in Figure 2. This figure shows how vacancy-posting varies with firm size in the three bargaining models, again in partial equilibrium, but in each of the two bargaining models, I reparameterize the multiplicative productivity term $A$ in the firm's production function so as to keep maximum firm size equal to its constrained efficient value of 23.8 in all cases. In this case, the pattern that small firms post relatively more vacancies in the constrained efficient allocation than in either of the two bargaining solutions manifests itself in greater vacancy-posting at all firm sizes. This is because in order for a firm bargaining with or without commitment to cease hiring at a size of 23.8, it must be less productive than the firms in the constrained efficient allocation, and therefore posts fewer vacancies at all sizes. The combination of Figure 1 and Figure 2 shows that in principle the pattern of vacancy posting across firms of different sizes can be used to identify the nature of bargaining in the economy, but that such a comparison must be made with care.

An alternative way of identifying the nature of bargaining between firms and workers arises from considering the increase in vacancy-posting in partial equilibrium of a firm whose productivity is 1 percent higher than all other firms in the economy. Intuitively, in a model with bargaining, we would expect to see such a firm increase its vacancy-posting less than the planner would like it to, since because of the rent-sharing resulting from bargaining, it does not capture the full return from its higher productivity, but only a fraction $1-\eta$. This can be verified numerically; in the constrained efficient allocation under the calibration with $\alpha=0.95$, for example, a one percent increase in productivity leads a firm with no workers to increase its vacancy-posting by around 8.8 percent, while under bargaining with commitment the increase is only 5.7 percent, and under bargaining without commitment, 6.1 percent. Thus, responsiveness of recruiting to idiosyncratic productivity shocks also helps in identifying the nature of contracting and wage determination.

Thus far, I reported only partial equilibrium comparisons, by studying the behavior of a single 

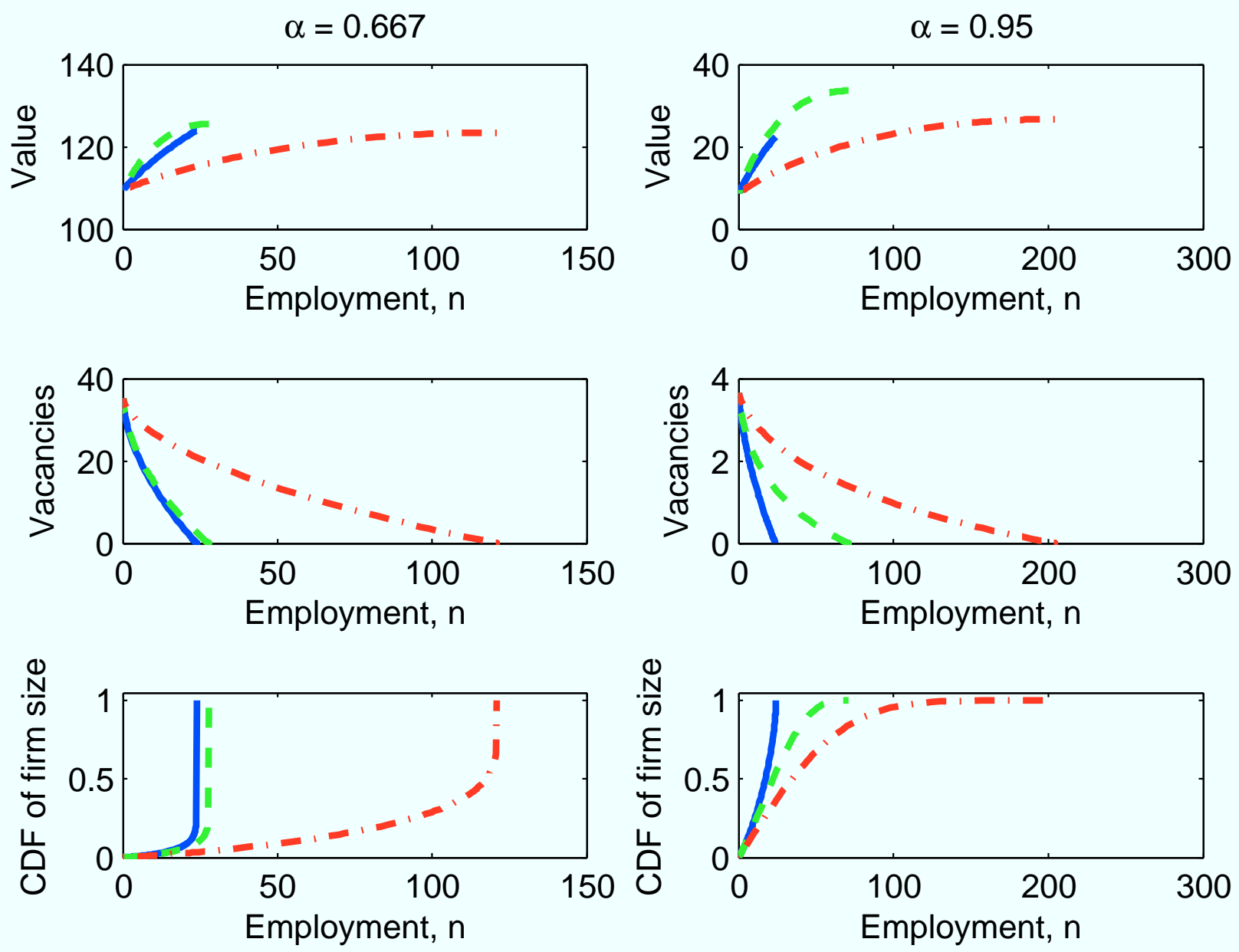

Figure 3: General equilibrium. The left three subfigures show results for the parameterization with $\alpha=0.667$, the right three for $\alpha=0.95$. In each case, the top figure shows firm's value functions, the center figure shows vacancy-posting, and the bottom figure shows the CDF of the firm size distribution. In each case, the blue solid curve shows the constrained efficient allocation, the green dashed curve shows bargaining with commitment, and the red dotted curve bargaining without commitment. 
firm which negotiates with its workers in various ways, but keeping the key endogenous variables $\theta$ and $V^{u}$ constant. General equilibrium comparisons, by contrast, are reported in Table 3 and Figure 3. More precisely, I now solve for the equilibrium of an economy in which the structural parameters are unchanged from before, but now all firms negotiate with workers according to bargaining with commitment. I then repeat the exercise in the case of bargaining without commitment. In this case, market tightness $\theta$ and the value of an unemployed worker $V^{u}$ are allowed to adjust so that the free entry condition of firms and the HJB equation defining the value of an unemployed worker are satisfied. Unsurprisingly in view of (6.1), welfare is lower under bargaining with commitment, and just as over-hiring is more severe under bargaining without commitment, so too is the inefficiency. When the production function is very concave $(\alpha=0.667)$, the welfare cost from bargaining with commitment under constant bargaining power is relatively small (0.3 percent). In this case, the high degree of decreasing returns limits over-hiring under bargaining with commitment and ensures the equilibrium allocation does not differ too much from its constrained efficient counterpart. Bargaining without commitment in this case, however, generates a large welfare cost (19.7 percent), as the very decreasing marginal product enables firms to drive down the wages of incumbent workers significantly by over-hiring. In contrast, when the production function is less concave $(\alpha=0.95)$, the relative differences in vacancy posting across firms of different sizes become more important, and welfare under bargaining with commitment falls by more ( 0.7 percent) relative to the constrained efficient allocation. The inability of firms bargaining without commitment to drive down wages significantly because of the slight degree of decreasing returns means that the welfare cost of bargaining in this case is much lower than before (2.3 percent), although still greater than under bargaining with commitment.

\section{Directed Search}

The next two sections of the paper are devoted to understanding the inefficiency result of Theorem 5.2 and Proposition 6.1 more deeply. In the current section, I consider a variant of the benchmark model in which workers are able to observe a single characteristic of firms, namely, their size, and condition their application decisions on that size. In the next section, I consider the case where there are constant returns in the vacancy-posting cost technology. In both cases, bargaining when workers have constant bargaining power equal to the Hosios value will decentralize the constrained efficient allocation, and it is informative to understand why.

Assume for now, therefore, that workers can direct their search activity according to easilyobservable firm characteristics. This was ruled out by assumption in the benchmark model, in which I assumed that an unemployed worker met a firm with $n$ incumbent workers in proportion to the measure of such firms, $g(n)$, and the intensity of vacancy-posting by them, $v(n)$. The worker was unable to affect her chances of meeting a firm with few employees that would pay a large hiring bonus, as opposed to a firm with many employees that would pay a small one. Instead, in this section, I assume that there are separate submarkets, indexed by the current employment of the 
firms who participate, so that all firms with a given number $n$ of employees post vacancies only in the submarket for firm with $n$ employees. The aim of this Section is to show that under this structure, the equilibrium allocation under bargaining with commitment is constrained efficient if and only if the Hosios condition holds.

Note that I do not assume that firms can post wages, as in directed search models following Moen (1997) and Shimer (1996). Wages continue to be determined by ex post bargaining. Workers can observe only the current employment level of the firm.

Before stating the main result of this section formally, I need to make the assumption on the matching technology more precise. At any moment of time, workers can search only in exactly one of the submarkets. It is frictionless to move from market to market, so that in equilibrium, workers will be indifferent between searching in each market. The value of home production, $b$, is independent of which market a worker searches in. The matching technology in each submarket is the same as the matching technology in the benchmark model. Specifically, if $u(n)$ unemployed workers search in the submarket for firms with $n$ current employees, in which there are $g(n)$ firms each posting $v(n)$ vacancies, then the flow rate of matches generated is $M(u(n), g(n) v(n))$. The Poisson rate at which an firm in this submarket contacts an unemployed worker is therefore $v(n) q(\theta(n))=$ $v(n) M\left(\theta(n)^{-1}, 1\right)$, where $\theta(n)=g(n) v(n) / u(n)$; the Poisson rate at which a worker contacts a firm is $f(\theta(n))=M(1, \theta(n))$.

I assume that bargaining proceeds as in the benchmark model, with firms and workers signing a simple contract at the time of hiring. The hiring bonus $h(n)$ continues to be given by (4). The HJB equation for a firm continues to be given by (6) with the exception that the hiring rate $q(n)=q(\theta(n))$ is now firm size-specific:

$$
(r+\delta) J(n)=y(n)-n r V^{u}-c(v(n))+(1-\eta(n)) q(n) v(n)[J(n+1)-J(n)]
$$

Optimal vacancy posting satisfies

$$
v(n)=\arg \max _{v}\{-c(v)+(1-\eta(n)) q(n) v[J(n+1)-J(n)]\} .
$$

The free entry condition (9) continues to hold.

Since workers can direct their search to any submarket, the flow value of an unemployed worker $r V^{u}$ must be equated across submarkets where positive numbers of unemployed workers search. That is,

$$
r V^{u}=b+f(n) h(n) \quad \text { if } \quad u(n)>0
$$

where $f(n)=f(\theta(n))$. In addition, if $u(n)=0$, the value of searching in submarket $n$ must be dominated by searching in other submarkets. The value of search in a submarket in which firms do not post a positive measure of vacancies is not well-defined. However, using the same intuitive argument as used by Acemoglu and Shimer (1999), I impose the equilibrium refinement that

$$
h(n) \leq 0 \quad \text { if } u(n)=0 \text { and } g(n)>0 .
$$


Intuitively, this condition requires that workers believe that if submarket $n$ is potentially open, in the sense that there are a positive measure of firms with $n$ workers, but if no workers are searching that submarket, then they would be able to obtain a job in that submarket instantaneously. Because no workers are searching the submarket, it follows that the signing bonus in this submarket must be non-positive, because the marginal product of firms with $n$ workers is low. ${ }^{10}$

The steady-state conditions for the constancy of the firm size distribution are analogous to equations (12) and (13), modified to allow for market tightness to differ across submarkets, so that

$$
(\delta+q(0) v(0)) g(0)=e
$$

and

$$
(\delta+q(n) v(n)) g(n)=q v(n-1) g(n-1) .
$$

Each unemployed worker must search precisely one submarket,

$$
\sum_{n=0}^{\infty} u(n)=u
$$

and market tightness in each submarket must be consistent with the vacancy-posting policy of firms and with the submarket choice of unemployed workers,

$$
\theta(n) u(n)=g(n) v(n)
$$

Finally, the unemployment rate must be constant, so that

$$
\delta(1-u)=\sum_{n=0}^{\infty} f(\theta(n)) u(n) .
$$

This allows me to make the following definition of equilibrium.

Definition 8.1 (Steady-state Equilibrium, Directed Search). A steady-state equilibrium under directed search is a sequence of market tightnesses $\theta(n)$, an unemployment rate $u$ and an allocation of unemployed workers across submarkets $(u(0), u(1), \ldots)$, an entry rate $e$, a firm size distribution $(g(0), g(1), \ldots)$, a vacancy-posting policy $(v(0), v(1), \ldots)$, a value of unemployment $V^{u}$, a sequence of values of firms $(J(0), J(1), \ldots)$, and a sequence of payments $(h(0), h(1), \ldots)$, such that

- $J(n)$ satisfies the HJB equation (27);

- $h(n)$ satisfies (4) for each $n$;

\footnotetext{
${ }^{10}$ This condition can be obtained more formally as an equilibrium refinement if one considers a variant of the current model in which there are a fraction $\varepsilon>0$ of firms who always post a positive measure $\delta>0$ of vacancies, no matter what the return to doing so. If a single worker considers searching submarket $n$, she expects that the market tightness will be unboundedly large in the case that no other workers are searching there, so that she will find a job instantaneously. She will therefore not search market $n$ only if $h(n) \leq 0$. This argument is independent of $\varepsilon>0$ (and of $\delta>0)$; taking a limit as $\varepsilon \rightarrow 0$ justifies (30).
} 
- $v(n)$ satisfies (28) for each $n$;

- the free entry condition (9) holds;

- $V^{u}$ satisfies $(29)$ and (30);

- the evolution of the firm size distribution and of the unemployment rate follow (31), (32), and (35);

- the allocation of unemployed workers to submarkets satisfies (33); and

- $\theta(n)$ satisfies (34) for each $n$.

Proposition 8.2 (Existence and Uniqueness of Equilibrium, Directed Search). A steady-state equilibrium under bargaining with commitment and directed search exists and is unique.

Denote by $n^{*}$ the largest firm size in equilibrium. The submarket for firms with $n^{*}$ workers is not open, so that no vacancies are posted and no unemployed workers search in this market. With this notation, I can state the following efficiency theorem.

Theorem 8.3 (Constrained Efficiency of Equilibrium under Hosios Condition, Directed Search). The steady-state equilibrium under bargaining with commitment and directed search is constrained efficient if and only if $\eta(n)=-\frac{\theta(n) q^{\prime}(\theta(n))}{q(\theta(n))}$ for all $n \leq n^{*}-1$.

Corollary 8.4. If the matching function is Cobb-Douglas, $M(U, V)=Z U^{\psi} V^{1-\psi}$, then the equilibrium is constrained efficient if and only if $\eta(n)=\psi$ for all $n \leq n^{*}-1$.

It is perhaps worth emphasizing that the result of Theorem 8.3 does not establish that the equilibrium allocation under directed search coincides with the constrained efficient allocation under random search, since the possibility of segregating different types of firms in submarkets characterized by different market tightnesses in the directed search setting allows the planner to generate strictly higher welfare in general. (The planner could always replicate the random search allocation in the directed search environment by generating the same market tightness in each submarket, but chooses not to do so since it is valuable to have small firms with high marginal products able to hire more rapidly, even conditional on the number of vacancies posted, than can larger firms with lower marginal products.)

Of course, because the equilibrium is constrained efficient in this environment, there is no role for corrective policy to improve on the equilibrium allocation. The planner has no reason to intervene.

The result of Theorem 8.3 clarifies why constrained efficiency fails to obtain when the bargaining power of workers is constant and satisfies the Hosios condition in the benchmark environment in which workers could not make their application decisions contingent on any characteristics of firms. The Hosios condition ensures that the private return to firms from posting vacancies equals the social return by ensuring that the value of payments made to workers exactly equals the congestion externality on other firms. However, it only does so if all firms in the labor market have the 
same value of hiring. Otherwise, the private cost to a firm if it hires is related, under bargaining, only to its own marginal value of hiring, while the cost of the congestion externality depends on the average value of hiring at other firms. When workers can direct their search to different submarkets containing firms of different sizes, each submarket contains only identical firms, and so the Hosios condition suffices to ensure constrained efficiency. When search is completely random, the labor market contains heterogeneous firms. Firms with many workers, that is, with low marginal products, make lower payments to the workers they hire than do firms with few workers and high marginal products. However, the congestion externality caused by vacancy posting is independent of the size of the firm. Therefore, constrained efficiency can obtain only if the bargaining power of workers covaries negatively with the marginal value of hiring in the appropriate way to ensure that the private benefit of hiring for a firm equals its social value.

A recent paper of Kaas and Kircher (2010), developed contemporaneously with the current paper, studies efficient hiring dynamics in a model closely related to the one presented in this section. Given the discussion so far, it should be clear why constrained efficiency obtains in their model. They assume commitment to long-term contracts, as I do, so that their allocation is not subject to the over-hiring inefficiencies present in models without commitment, such as those by Stole and Zwiebel (1996a,b), Smith (1999), and Cahuc and Wasmer (2001). In addition, they assume that workers can direct their search not towards size classes of firms, but towards contracts to which these firms commit. Relative to a random search model, this ensures both that the economy endogenously separates into submarkets according to the size classes of firms, and that within each submarket, the Hosios condition obtains. Therefore the allocation generated in their model is identical to that generated in the directed search model of the current section (and generates a higher welfare).

\section{Hiring at Constant Marginal Cost}

In this section, I return to the setting of random search, but now modify the benchmark model by assuming that the marginal cost of posting vacancies is constant, rather than increasing in the firm's vacancy posting. This is the assumption made by Smith (1999) and Elsby and Michaels (2010) when studying bargaining without commitment. In this environment, both equilibrium and constrained efficient allocations are easier to characterize, since the optimal vacancy-posting behavior of firms takes a particularly simple form: at the moment of entry, a new firm posts a very large measure of vacancies for a very short time, so as to grow instantaneously to its desired target size. In this environment, it also turns out that the efficiency properties of bargaining with commitment are stronger: the Hosios condition suffices for constrained efficiency of equilibrium. Understanding why clarifies the intuition for Theorem 5.2 and Proposition 6.1, the main efficiency results of the benchmark model.

Because it will be unnecessary to allow for the bargaining power of workers to vary with firm size, I simplify notation by specializing to the case where $\eta(n) \equiv \eta$. As in the benchmark environment of 
Section 3, I continue to assume that when a worker is matched with a firm, a long-term contract is signed which guarantees an immediate payment of $h(n)$ and ongoing payments equal to $r V^{u}$, with $h(n)$ is chosen to maximize (3).

To see that optimal hiring in the case when $c(v) \equiv \gamma v$ takes a 'bang-bang' form, consider the problem of a firm with $n$ workers that is deciding its vacancy posting intensity. If it posts vacancies with a finite intensity $v \in(0, \infty)$ until it hires its $(n+1)$ st worker and then returns to the optimal vacancy-posting strategy, then its value $J(n ; v)$ satisfies the HJB equation

$$
(r+\delta) J(n ; v)=y(n)-n r V^{u}-\gamma v+q(\theta) v(1-\eta)[J(n+1)-J(n ; v)] .
$$

The right side of (36) is an affine function of $v$, so that $J(n ; v)$ is maximized by setting $v \rightarrow+\infty$ if $-\gamma+q(1-\eta)[J(n+1)-J(n)]>0$ and $v=0$ if $-\gamma+q(1-\eta)[J(n+1)-J(n)]<0$. This establishes the optimality of the 'bang-bang' vacancy posting strategy. If $v \rightarrow \infty$, then rearranging the right side of $(36)$ and putting $J(n)=\max _{v} J(n ; v)$ establishes that

$$
J(n+1)=J(n)-\frac{1}{1-\eta} \frac{\gamma}{q(\theta)} .
$$

That is, with linear vacancy-posting costs, firms can effectively hire additional workers instantaneously at a constant marginal cost equal to $\frac{1}{1-\eta} \frac{\gamma}{q(\theta)}$; the model reduces to an adjustment cost model in which adjustment costs apply only to firms increasing their employment, and in which these adjustment costs increase with the worker's bargaining power $\eta$ and with the tightness of the labor market. This is intuitive. If the labor market is tighter, there is a direct effect of increasing vacancy posting costs, and in addition, the greater vacancy-posting costs then lead to a higher lump-sum payment $h(n)$ bargained with a new hire. The latter effect is stronger the higher the worker's bargaining power. Using (4), it can be seen that the hiring bonus paid to a new hire is

$$
h(n)=\frac{\eta}{1-\eta} \frac{\gamma}{q(\theta)} .
$$

As already discussed, a new entrant firm instantaneously increases its employment level until it hits its target firm size $n^{*}$. A firm with employment equal to its hiring target $n^{*}$ will never change its employment level in future since there are no aggregate or idiosyncratic shocks, so that its HJB equation takes the simple form

$$
(r+\delta) J\left(n^{*}\right)=y\left(n^{*}\right)-n^{*} r V^{u}
$$

For $n>n^{*}$, but such that $y(n)-y(n-1) \geq r V^{u}$, a firm will neither hire nor fire workers, so that in this range also

$$
(r+\delta) J(n)=y(n)-n r V^{u} .
$$

For $n$ large enough that $y(n)-y(n-1)<r V^{u}$, the optimal long-term contract signed by firms and workers will specify that separation occur immediately for enough workers to reduce $n$ to 
the value $\bar{n}$ defined by $y^{\prime}(\bar{n})=r V^{u}$. In this case, therefore, $y(n)=y(\bar{n})$. Finally, for a firm with current employment $n$ smaller than $n^{*}$, the optimal hiring policy requires immediate hiring of $n^{*}-n$ workers. According to (37), each employee already hired means an increase in the firm's value of $\frac{1}{1-\eta} \frac{\gamma}{q}$, so that for $0 \leq n<n^{*}, J(n)=J\left(n^{*}\right)-\frac{1}{1-\eta} \frac{c}{q} n$. In summary, the value of a firm takes the form

$$
J(n)= \begin{cases}\frac{y\left(n^{*}\right)-n^{*} r V^{u}}{r+\delta}-\frac{1}{1-\eta} \frac{c}{q} n & 0 \leq n<n^{*} \\ \frac{y\left(n^{*}\right)-n^{*} r V^{u}}{r+\delta} & n=n^{*} \\ \frac{y(n)-n r V^{u}}{r+\delta} & n^{*}<n \leq \bar{n} \\ \frac{y(\bar{n})-\bar{n} r V^{u}}{r+\delta} & n>\bar{n} .\end{cases}
$$

The optimal choice of the hiring target $n^{*}$ is the (generically unique) value satisfying

$$
\frac{y\left(n^{*}\right)-y\left(n^{*}-1\right)-r V^{u}}{r+\delta}>\frac{1}{1-\eta} \frac{\gamma}{q(\theta)} \geq \frac{y\left(n^{*}+1\right)-y\left(n^{*}\right)-r V^{u}}{r+\delta}
$$

similarly, the firing target $\bar{n}$ is the smallest value satisfying $y(\bar{n})-y(\bar{n}-1) \geq r V^{u}$.

In equilibrium, the free-entry condition requires that $V^{u}$ and $q=q(\theta)$ be such that the free entry condition (9) holds, that is,

$$
k=J(0)=\frac{y\left(n^{*}\right)-n^{*} r V^{u}}{r+\delta}-n^{*} \frac{1}{1-\eta} \frac{\gamma}{q}
$$

The final key equilibrium equation is the HJB equation of a worker. This takes the form

$$
r V^{u}=b+f(\theta) \frac{\eta}{1-\eta} \frac{\gamma}{q}=b+\frac{\eta}{1-\eta} \theta \gamma
$$

since an unemployed worker encounters a firm at Poisson rate $f(\theta)$, at which point she receives a hiring payment of $h(n)=\frac{\eta}{1-\eta} \frac{\gamma}{q}$ and thereafter flow payments that make her indifferent to being unemployed.

The remaining equations required to define a steady-state equilibrium require that the unemployment rate evolve according to (14), unchanged from the environment of Section 3, and that the flow entry rate of new firms be such that the ratio of vacancies to unemployed workers is consistent with the value of market tightness $\theta$, that is,

$$
\theta u=\frac{e n^{*}}{q(\theta)}
$$

The preceding set of equations allows me to define a steady-state equilibrium in this environment.

Definition 9.1 (Steady-state Equilibrium, Constant Hiring Cost). A steady-state equilibrium with constant hiring cost is a market tightness $\theta$, an unemployment rate $u$, an entry rate e, a target firm size $n^{*}$, a value of unemployment $V^{u}$, a value function for firms $J:[0, \infty) \rightarrow \mathbb{R}$, and a payment function $h:[0, \infty) \rightarrow \mathbb{R}$, such that entering firms instantaneously hire $n^{*}$ workers, and such that 
- $J(n)$ satisfies (39);

- the free entry condition (41) holds;

- $V^{u}$ satisfies (42);

- the evolution of the unemployment rate follows (14); and

- $\theta$ satisfies (43).

Proposition 9.2 (Existence and Uniqueness, Constant Hiring Cost). There is a generically-unique equilibrium when the marginal cost of vacancy-posting is constant.

In steady-state equilibrium, there is a constant flow rate of entry $e>0$ of firms who, on entry, immediately grow to size $n^{*}>0$, which satisfies

$$
n^{*}=\arg \max _{n} \frac{1}{n}[y(n)-(r+\delta) k] .
$$

In the generic case where (44) has a unique solution, the equilibrium is unique. After their initial burst of hiring, firms never change their size. The values of the two key endogenous variables $\theta$, which affects the cost of hiring via the vacancy yield $q(\theta)$, and $V^{u}$, which affects wages, are then jointly determined from the free entry condition (41) and the HJB equation for an unemployed worker, (42). Uniqueness of equilibrium is easier to prove in this environment than in the benchmark model, since the firm size distribution does not depend on $\theta$ and $V^{u}$. Therefore, Proposition 9.2 establishes existence and uniqueness, where Proposition 4.2 established only existence of equilibrium.

Is the equilibrium constrained efficient in this environment? To answer this question, it's first necessary to characterize constrained efficient allocations. The same argument as used for the decentralized economy implies that the planner also chooses a 'bang-bang' vacancy-posting policy for all firms. In this case, a steady-state constrained efficient allocation can be represented as a tuple $\left(e, n^{*}, \theta, u\right)$ consisting of a flow entry rate of firms $e$, a hiring target $n^{*}$, a market tightness $\theta$, and an unemployment rate $u$ which jointly solve

$$
\max _{e, n^{*}, \theta, u} \int_{0}^{\infty} e^{-r t}\left(\left[\frac{y\left(n^{*}\right)}{r+\delta}-n^{*} \frac{\gamma}{q(\theta)}-k\right] e+b u\right) d t
$$

subject to

$$
n^{*} e=\theta q(\theta) u=f(\theta) u \quad \text { and } \quad \dot{u}=\delta(1-u)-\theta q(\theta) u \text {. }
$$

The two constraints are that hiring by entrant firms be consistent with the outflow from unemployment, and the law of motion for the unemployment rate. ${ }^{11}$

\footnotetext{
${ }^{11}$ The reader may wonder why the distribution of existing firms is not a state variable in the planner's problem. Formally, what the program (45) and (46) analyzes is a problem where the planner's two key control variables at each moment are the flow entry rate of new firms, $e$, and the size these firms immediately grow to, $n^{*}$. The planner does not consider the possibility of changing the size of incumbent firms, either by hiring or firing. These firms are 'sunk'
} 
First, independent of the value of the bargaining power of workers, (44) shows immediately that the size of firms is always constrained efficient in equilibrium. Both the planner and firms in the decentralized equilibrium choose a hiring target $n^{*}$ so that the marginal additional output from hiring an additional worker is equal to total output less the amortized entry cost, divided by the number of employees. ${ }^{12}$ This is just the familiar condition that average and marginal product coincide at the efficient firm scale.

Proposition 9.3 (Efficient Hiring, Constant Hiring Cost). The equilibrium hiring target $n^{*}$ is constrained efficient.

Proposition 9.3 implies that any discrepancy between the equilibrium allocation under bargaining with commitment and the constrained efficient allocation arise from differences in market tightness. However, because the value function of a firm is linear in employment up to the hiring target $n^{*}$, the Hosios condition is now necessary and sufficient for constrained efficiency. The source of inefficiency that arose in the benchmark model if workers' bargaining power was constant with firm size cannot arise here, since there is no sense in which firms with different employment levels can use the wrong intensity of vacancy posting relative to each other: all firms hire all their workers instantaneously on entering.

Proposition 9.4 (Hosios Condition, Constant Hiring Cost). The equilibrium under bargaining with commitment is constrained efficient if and only if

$$
\eta=-\frac{\theta q^{\prime}(\theta)}{q(\theta)} .
$$

In the statement of Proposition 9.4, the value of $\theta$ referred to is the constrained efficient value (which coincides with the equilibrium value under the assumption of the proposition).

Why is the equilibrium constrained efficient under the Hosios condition in the case of constant hiring costs, according to Proposition 9.4, whereas in general Theorem 5.2 and Proposition 6.1 showed that more stringent conditions were needed for constrained efficiency when search is random? The reason is that constant hiring costs imply, as in (39), that the value function of a firm is linear in employment for firms that are hiring any workers. This means that the marginal incentive to hire for a firm is independent of the number of workers it has already hired. Therefore, the condition that the Hosios condition needs to hold on average, true even in the general case according to Corollary 5.3, here takes a particularly simple form: having the bargaining power of each worker equal to the elasticity of the matching function suffices to make firms internalize the congestion externality they impose on other firms. ${ }^{13}$

from the point of view of the planner, since the present discounted value of the output of a firm is accounted for in (45) at the moment it is formed. However, in steady state, the value of this restricted problem and the allocation so generated are the same as in the more general problem where the planner avails herself of the full set of tools available to her, since there is no reason to change the size of existing firms after their initial growth at entry. This trick, which simplifies the notation, is borrowed from Acemoglu and Shimer (1999).

${ }^{12}$ This again makes it apparent why it was necessary to assume a non-zero entry cost $k$ : if $k=0$, optimal firm size is $n^{*}=0$, and the model reduces to the MP limit.

${ }^{13}$ In fact, because of the 'bang-bang' nature of hiring, if the bargaining power of workers were allowed to vary with 


\section{The Role of Commitment and the Timing of Payments}

When I introduced the benchmark contracting assumption of the model in Section 3, I assumed full commitment of firms and workers to contracts signed at the moment of hiring. In this section, I discuss the roles of these assumptions and the extent to which they can be weakened. The next section concludes the paper by discussing its relationship with the literature.

First, of course, the contracts considered in this paper are not the most general contracts that could be considered. In particular, I assume that the contracts a firm signs with workers it hires early in its growth process cannot affect the nature of contracts the firm signs when a new hire later occurs, nor its bargaining power when it negotiates a division of the marginal surplus with that new hire. Thus, the contracting arrangements I present are not intended as models of union bargaining, to give an example in which such contractual arrangements might be reasonable. ${ }^{14}$ Casual empiricism suggests that contracts of individual workers with large non-unionized firms tend not to have such features, justifying the relevance of the contracting environment I consider. Additionally, as Smith (1999) argues, allowing the right to manage to each individual worker might be ruled out in a more complete model due to the costs of coordination between many workers, as well as by the costs of aligning the incentives of the firm's owners and its employees. Moreover, the assumption I make here is also made both by authors studying large firms in a random search model without commitment (Stole and Zwiebel, 1996a,b; Smith, 1999; Cahuc and Wasmer, 2001), as well as to the case of directed search (Hawkins, 2006; Kaas and Kircher, 2010). ${ }^{15}$

In addition, to obtain constrained efficiency in the benchmark model requires that the bargaining power of a new worker be increasing in firm size. It is not obvious why allowing incumbent workers the right to manage the firm would have any tendency to lead to such an outcome.

What role does the ability of firms and workers to commit to the terms of a contract signed at the time of hiring play in the results of the paper? Under the benchmark contracting environment introduced in Section 3, the importance of commitment is that workers can commit not to renegotiate after the moment of hiring. Intuitively, in the absence of commitment, incumbent workers would like to force a renegotiation of wages if they could: they are paid only the flow value of

firm size, it is clear that having $\eta(n)$ constant and given by (47) is not the only way to generate constrained efficiency here; what matters is that bargaining power should equal the Hosios value on average. One can show in a version of the model in which bargaining power varies with firm size that the necessary and sufficient condition for efficiency is, as in (5.3), that a harmonic mean of bargaining powers by firm size should take the correct value, specifically that

$$
\int_{0}^{n^{*}} \frac{d n}{1-\eta(n)}=\frac{1}{1-\eta}
$$

\footnotetext{
${ }^{14}$ Bauer and Lingens (2010) consider a model of collective bargaining between workers and large firms in a context similar to that considered here, with different positive and normative predictions; in particular, the ability of workers to threaten at any time to withhold their labor en masse tends to drive up wages and reduce hiring inefficiently.

${ }^{15}$ Sufficiently general contracts (for example, signed by all agents in the economy) could of course restore efficiency according to the Coase theorem; however, allowing firms and workers who have never met to have signed ex ante a contract influencing their behavior (and in particular, the intensity with which firms post vacancies in order to meet these workers) is implausible and is ruled out by assumption in all models of frictional labor markets to my knowledge.
} 
being unemployed for the entire remaining duration of their contract, while a newly-hired worker extracts positive surplus above this amount from the firm according to (3). (Firms, on the other hand, would not wish to trigger a renegotiation with incumbent workers even if they could do so, since incumbent workers are already receiving the lowest wage consistent with them not desiring to quit to unemployment if they had the opportunity to do so; therefore firms have nothing to gain from renegotiation.) It is uncontroversial to assume that firms have some ability to commit to contracts, but perhaps more troublesome to assume that workers can bind themselves by longterm contracts of the form considered here. It is therefore useful to note that changing the timing of payments within an employment relationship can reduce the importance of the assumption of commitment by workers. I now proceed to consider several possible alternative assumptions on how payments are made during an employment spell.

First, an obvious alternative payment scheme is that instead of paying a lump sum on hiring, firms might annuitize the value of that lump sum over the life of the employment relationship. That is, instead of paying $h_{t}(n)$ at the moment when a worker is hired by a firm with $n$ incumbent workers, as well as a wage of $r V_{t+\tau}^{u}$ at all times $t+\tau \geq t$ until the end of the employment spell, the firm might instead pay no hiring bonus and a flow wage of $(r+\delta) h_{t}(n)+r V_{t+\tau}^{u}$ at all $t+\tau \geq t$. Clearly such a wage contract generates the same expected present discounted value for the worker as the original payment program did. However, because $h_{t}(n)$ is decreasing in $n$ when the production function is concave and hiring is time-consuming, later hires are in this scheme paid lower wages than early hires, and these wages are therefore higher than incumbent workers would be able to negotiate if they were forced to rebargain according to the same procedure used at the time they were hired. Under this kind of arrangement, the role of commitment is to guarantee that the firm can commit to pay wages to workers as specified in the initial contract, since workers would no longer be tempted to renegotiate contracts.

An interesting alternative payment scheme that reduces further the importance of commitment by both firms and workers can be generated if I assume that in addition to a wage, firms can commit to pay transfers to incumbent workers at the time when a new employee is hired. In particular, suppose that at the time of hiring, a new employee's contract can specify that she receives a flow wage $w_{t}(n)$ whenever the employment of the firm equals $n$, and in addition, that she receives a lump-sum transfer of $p_{t}(n)$ whenever the firm hires an $(n+1)$ st worker. (There is no longer a lump-sum transfer to a newly-hired worker.) Suppose that

$$
w_{t}(n)=r V_{t}^{u}+(r+\delta) h_{t}(n-1)
$$

and

$$
p_{t}(n-1)=h_{t}(n-1)-h_{t}(n)
$$

where $h_{t}(\cdot)$ are the hiring bonuses specified in the benchmark payment timing according to (4). Then one can verify first that if the firm's vacancy-posting policy is unchanged from the benchmark, then the value of this payment scheme leaves unchanged the expected present discounted value of 
payments by the firm to each employee, and also leaves the firm's cost of hiring unaltered. To see the first of these, let $\hat{h}_{t}(n-1)$ denote the expected present discounted value of the surplus payments (over and above the value of unemployment) to be received by a worker hired by a firm with $n-1$ incumbent workers. $\hat{h}_{t}(n-1)$ satisfies the Hamilton-Jacobi-Bellman equation

$$
(r+\delta) \hat{h}_{t}(n-1)=\left[w_{t}(n)-r V_{t}^{u}\right]+q_{t} v_{t}(n)\left[p_{t}(n)+\hat{h}_{t}(n)-\hat{h}_{t}(n-1)\right] .
$$

Equation (50) takes into account that the stream of wage payments equal to $w_{t}(n)$ end either when the firm is destroyed or when it hires a new worker. In the first of these cases, the payments simply stop; in the second, the worker receives a transfer $p_{t}(n)$, and the new expected value of future wage payments and transfers from that date on is $h_{t}(n)$. It is easy to verify that $\hat{h}_{t}(n)=h(n)$ for all $n$, which establishes the first claim. Moreover, under the benchmark timing of payments, the total stream of payments to the $n$ th-hired worker, over and above the flow value of being unemployed, is simply the hiring bonus $h_{t}(n-1)$; under the alternative payment timing, the firm replaces a commitment to pay each of its $n-1$ incumbent workers a stream of payments with EPDV just shown to be equal to $h_{t}(n-1)$, with a commitment to pay each of its incumbent workers a transfer $p_{t}(n-1)$ and each worker, new or old, a stream of payments with EPDV $h_{t}(n)$. It is easy to verify that

$$
h_{t}(n)=n h_{t}(n)+(n-1)\left[p_{t}(n-1)-h_{t}(n-1)\right]
$$

so that the cost of hiring is also unchanged. This implies that the firm's vacancy-posting strategy will also remain unchanged from the benchmark payment timing.

This payment scheme is attractive since it reduces the extent to which I need to assume that firms and workers can commit to long-term contracts. Because incumbent workers are now treated identically to new hires at all dates after the instant of hiring, it is not necessary to assume, as was done in (3), that only new hires have the ability to extract positive surplus from the firm. Instead, I can assume that at any time, any individual worker can threaten to withdraw her services from the firm and return to unemployment. I assume that if this happens, it triggers a pairwise negotiation in which the surplus $\left[J_{t}(n)-J_{t}(n-1)\right]+h_{t}(n)$ associated with the bilateral relationship is split in ratio $\eta(n):(1-\eta(n))$ between the firm and the worker. If payments are characterized by (49) and (48), then this split is already guaranteed by the existing contract, so that there is no incentive for the worker (or, indeed, for the firm) to trigger such a renegotiation. At the moment when hiring of a new worker occurs, all incumbent workers are given the transfer payment $p_{t}(n-1)$ which makes them indifferent between being employed by the firm with $n-1$ or with $n$ workers, so that they have no incentive to object to the firm's hiring decision either. (Off the equilibrium path, if a worker were to quit or be fired by the firm, I need to assume that this triggers a lump-sum payment of $p_{t}(n-1)$ from each incumbent worker to the firm, so that this payment scheme does have one drawback in an environment where separations occur in equilibrium.) The commitment power of firms to make the transfer payments specified in the contract does, however, continue to be important. 
Finally, one might object to the plausibility of this last payment scheme that explicit transfers to incumbent workers when firms hire new employees are not commonly observed explicitly. However, note that if the firm's employment is a continuous variable and a law of large numbers applies at the firm level, as in Section 9, then hiring becomes a flow and is deterministic rather than stochastic. In this case, the transfer payments to be made to workers at the moment when new workers are hired become a continuous stream of flow payments. This would be indistinguishable empirically from a flow wage, and would completely remove the need for lump sum transfers.

\section{Relationship to the literature}

There is a burgeoning literature on models of large firms operating in a frictional labor market. When wages are bargained, the most frequently cited model of this literature is the model of bargaining without commitment due to Stole and Zwiebel (1996a,b). Stole and Zwiebel studied an economic setting characterized by what they term ${ }^{16}$ an 'extreme employment-at-will' assumption: firms and workers are unable to commit to any form of long-term contract over wages or employment levels. Wages are bargained according to a rule that divides the flow marginal surplus generated by the employment relationship in a known ratio; perhaps the most important contribution of Stole and Zwiebel's work is to provide both cooperative and noncooperative microfoundations for bargaining over the marginal surplus, at least in a static setting.

A well-known feature of the model of bargaining without commitment is the over-hiring result already referred to. When the production technology exhibits decreasing returns to scale, wages decrease with the number of workers in the firm, and this gives firms an incentive to 'over-hire' workers to the point that the wage paid exceeds their marginal product. Stole and Zwiebel established this result in a static partial equilibrium environment; Smith (1999) and Wolinsky (2000) show that the over-hiring result is true also in a dynamic general equilibrium setting. My analysis in this paper differs in that I make the polar opposite assumption from employment-at-will, and instead assume that firms and workers have full powers of commitment to contracts once matched. The inefficiency arising in their model occurs because, even after being matched, a firm and its workers cannot commit to the jointly Pareto-superior plan that would lead the firm to hire the efficient number of workers. The intuition of the Coase theorem, and the casual empirical observation that formal labor contracting is ubiquitous in large firms, makes it surprising that the firm and its workers cannot bind themselves jointly to a contract to remove the inefficiency.

By contrast, the efficiency arising in this paper under bargaining with commitment and constant bargaining power is a search externality, and could only be overcome by contracts written among all the workers and firms in the entire economy. It seems uncontroversial to assume, as I do, that small costs of contracting mean that such overarching contracts cannot be written. It seems strange to assume, as earlier authors do, and without further justification, that a firm is unable to contract in a jointly privately efficient way with its workers when casual empiricism suggests that formal

\footnotetext{
${ }^{16}$ Stole and Zwiebel (1996a, p. 377).
} 
labor contracting is ubiquitous in large firms.

Other authors using the framework of bargaining without commitment and random search in recent models of large firms include Cahuc and Wasmer (2001), Cahuc, Marque and Wasmer (2008), and Mortensen (2009); none of these authors focus on the efficiency question studied here. Wolinsky (2000) and Acemoglu and Hawkins (2010) study versions of the SZ model in which hiring is time-consuming. Applications of the basic framework have recently also included work studying wage determination (Roys, 2010), the interaction of product market regulation and the labor market (Felbermayr and Prat, 2007; Delacroix and Samaniego, 2009; Ebell and Haefke, 2009), trade (Coşar, Guner and Tybout, 2010; Helpman and Itskhoki, 2010), as well as several others; all these authors simply take the assumption of bargaining without commitment as axiomatic when large firms bargain with their employees. Thus, it remains unclear to what extent their results rely on deep features of the economic environments they study, and to what extent any policy recommendations they derive arise from the assumption of the inability of firms and workers to commit to contracts.

In a recent working paper, Bauer and Lingens (2010) modify the bargaining protocol between firms and workers differently from the way I do. They remove the firm's incentive to over-hire workers by assuming that the firm bargains collectively with all its workers simultaneously, and that the entire workforce jointly decides whether or not to work. They argue that this leads to efficient hiring conditional on the value of an unemployed worker, but that it also leads to this value being excessively high, so that under-hiring instead results. That is, the equilibrium in their model is also not constrained inefficient, but for a very different reason from the one I study in this paper, in which I assume that firms bargain individually with each of their workers, but only at the moment of hiring rather than continuously.

More generally, the efficiency of equilibria in models where wages are set by bargaining between workers and firms is a much-studied area. Of particular relevance to this paper is the seminal contribution of Hosios (1990), who established the relationship between bargaining power and the elasticity of the matching function with respect to unemployment. Acemoglu and Shimer (1999) generalize this, and my paper borrows some techniques from them (in particular, the result of Theorem 8.3 that the equilibrium is constrained efficient when the Hosios condition applies and firms can direct their search to the size of firms is reminiscent of results obtained in that paper).

Moen (1997) and Shimer (1996) showed that constrained efficiency obtains more generally in models of directed search, both via the separation of agents with different marginal benefits of hiring into different submarkets and via ensuring that the wage paid by firms in each submarket is the same as that generated by bargaining under the Hosios condition. As is clear from Theorem 5.2, Proposition 6.1, and Theorem 8.3, simply bargaining under the Hosios condition without separation into submarkets does not generate an equilibrium allocation that is constrained efficient. The relationship with the efficiency results of Kaas and Kircher (2010) has already been discussed in Section 8; my paper clarifies the constrained efficiency result in their model. ${ }^{17}$

\footnotetext{
${ }^{17}$ Directed search models of hiring by large firms in frictional labor markets are also studied by Hawkins (2006),
} 


\section{Conclusion}

The question of how bargaining occurs between workers and firms is key for understanding both empirical predictions and the policy recommendations arising from studying models of frictional labor markets. In this paper, I propose a model of bargaining with random search that avoids the failure of firms and workers to contract on privately efficient actions enshrined in theoretical and applied work following Stole and Zwiebel (1996a,b), Smith (1999), and Cahuc and Wasmer (2001).

Removing one inefficiency allows me to highlight another, one which is also in fact present in the models of the previously-mentioned authors in the realistic case that hiring is time-consuming. Even when firms can commit to long-term contracts, the equilibrium is not constrained efficient even when the Hosios (1990) condition holds. The reason for the inefficiency lies in the random nature of search. If bargaining power is constant across firms, then firms of different sizes and productivities will not face the correct incentive to hire additional workers. Firms with a high marginal product of labor face too low an incentive to hire, so that they post too few vacancies and grow too slowly; firms with a low marginal product of labor earn too high a return from hiring, so that they post too many vacancies and grow too fast. In fact, the pattern of vacancy-posting across firms, and the resulting pattern of firm growth rates by firm size, is diagnostic of whether an allocation is constrained efficient, or arises from bargaining either with commitment or without. The inefficiency arising from random search manifests itself as over-hiring, in the sense that the largest firms in equilibrium are larger than the planner would prefer them to be, although not as large as under bargaining without commitment. The welfare cost of the inefficiency I identify can be of nearly the same order of magnitude, however, at least in the empirically-plausible case when the decreasing returns to labor in production are not too severe.

The importance of the inefficiency studied in this paper is ultimately empirical: it relies on identifying how workers and firms bargain with each other and what kinds of contracts they can sign. In principle, the growth paths of firms (or equivalently, the pattern of vacancy-posting across firms of different sizes) can be used to identify the nature of bargaining when hiring is time-consuming, and in fact, can potentially also help with the challenging research question of distinguishing between random and directed search in the labor market. Using the wealth of information on firm dynamics from data sources like the Job Openings and Labor Turnover Survey to shed light on these issues seems a promising area for future research.

\section{A Omitted Proofs}

This Appendix contains statements of some definitions and results that are not formalized in the text, together with all technical proofs.

Proof of Proposition 4.2. First note that, taking the values of $\theta$ and of $V^{u} \geq b$ as given, the problem of a firm is summarized by (6), with vacancy posting $v(n)$ satisfying (7). Because $y(\cdot)$ is strictly

Lester (2010) and Tan (2010). 
concave and satisfies $y^{\prime}(n) \rightarrow 0$ as $n \rightarrow \infty$, it follows that for large enough $n, y^{\prime}(n)<V^{u}$, so that there is a value $n^{*} \geq 0$ such that $v(n)>0$ iff $n<n^{*}$. It is then immediate that $J\left(n^{*}\right)=$ $\left[y\left(n^{*}\right)-n^{*} r V^{u}\right] /(r+\delta)$. (5), or equivalently, (6) and (7), can then be solved recursively for $J(n)$ for $0 \leq n \leq n^{*}$. To see this more clearly, rewrite (5) as

$$
\begin{aligned}
(r+\delta)[J(n+1)-J(n)]+\max _{v}\{-c(v)+q v(1-\eta(n)) & {[J(n+1)-J(n)]\} } \\
& =(r+\delta) J(n+1)-y(n)+n r V^{u} .
\end{aligned}
$$

The left side of this equation is an increasing function of $J(n+1)-J(n)$, and therefore a decreasing function of $J(n)$; the right side is independent of $J(n)$, so that there is a unique solution for $J(n)$ given the value of $J(n+1)$. Continuing recursively, I can then solve for the implied value of $J(0)$, the value of a firm that posts vacancies optimally in future, taking as given the values of $\theta$ and of $V^{u}$. Moreover, the vacancy posting policy of firms is uniquely defined since $v(n)>0$ for $n<n^{*}$, so that $v(n)$ satisfies the first-order condition (7); if $n \geq n^{*}$ then $v(n)=0$. The steady-state equations for the firm-size distribution (12) and (13) can then be solved to determine the firm size distribution conditional on the flow rate of entry $e$. Note that the ratios $g(n) / g(m)$ for $0 \leq n, m \leq n^{*}$ are independent of $e$.

Using the argument of the previous paragraph, I can therefore define two functions $\chi, \omega$ : $\mathbb{R}_{+} \times \mathbb{R} \rightarrow \mathbb{R}$ as follows.

- $\chi\left(\theta, V^{u}\right)$ is the value of $J(0)$ obtained by a firm taking $\theta$ and $V^{u}$ as given and posting vacancies optimally; and

- $\omega\left(\theta, V^{u}\right)$ is the value $r V^{u}-\left[b+f(\theta) \frac{\sum_{n=0}^{\infty} g(n) v(n) \eta(n)[J(n+1)-J(n)]}{\sum_{n=0}^{\infty} g(n) v(n)}\right]$ produced using the solution for $J(\cdot)$, the vacancy-posting policy $v(n)$, and the firm size distribution $g(n)$ given that all firms behave as in the previous paragraph.

Note that $r V^{u}-\omega\left(q, r V^{u}\right)$ is just the expression on the right side of (10) for the value of an unemployed worker in an economy populated by firms behaving as already characterized. It is clear that $\left(\theta, r V^{u}\right)$ is part of an equilibrium allocation iff

$$
\begin{aligned}
& k=\chi\left(\theta, V^{u}\right) \\
& 0=\omega\left(\theta, V^{u}\right) .
\end{aligned}
$$

(To construct the remainder of the equilibrium allocation, choose $e$ so that (15) is satisfied; the remaining equilibrium conditions are satisfied by construction.) It is immediate that (52) defines a continuous 1-manifold in $\mathbb{R}^{+} \times \mathbb{R}$ (if either $\theta$ or $V^{u}$ change slightly, then the value of $J(0)$ implied by (5) is only slightly modified, and it is clear that this value is strictly decreasing in both $\theta$ and $V^{u}$ if there is positive activity in equilibrium, so that there are active firms in equilibrium). It is therefore sufficient to show that $\omega$ restricted to this manifold defines a continuous function which takes both positive and negative values; the intermediate value theorem then gives the result.

To see this, first define $\bar{v}$ to solve

$$
k=\frac{1}{r+\delta} \max _{n>0}[y(n)-n \bar{v}] .
$$

A firm that pays flow payment of $\bar{v}$ to each of its employees will just break even if and only if it can reach the employment level $n^{*}$ that maximizes the right side of (54) instantaneously on entry and at zero cost. (If it does so, then the hiring payments $h(n)$ will be zero for each $n$.) It follows that $\lim _{\theta \rightarrow 0} \chi(\theta, \bar{v})=k$. Also, for $v>\bar{v}, \chi(\theta, v)<k$ by construction. Now, if $\theta \rightarrow 0$, then any firm 
will instantaneously hire $n^{*}$; thus in the limit, $J(n)=J\left(n^{*}\right)$ for all $n \in\left[0, n^{*}\right]$. From the definition of $\omega(\cdot)$, it follows that in this case, $\omega(\theta, \bar{v})=\bar{v}-b$. This is strictly positive by (2).

In the other extreme, let $\hat{\theta}>0$ satisfy $\chi(\hat{\theta}, b)=0$. Such a $\hat{\theta}$ will exist provided that $\bar{v}>b$; assume this. By definition,

$$
\omega(\hat{\theta}, b)=-f(\hat{\theta}) \frac{\sum_{n=0}^{n^{*}} g(n) v(n) \eta(n)[J(n+1)-J(n)]}{\sum_{n=0}^{n^{*}} g(n) v(n)}
$$

If $\hat{\theta}$ is positive, then $f(\hat{\theta})>0$, and $J(n+1)-J(n)>0$ for each $n$. Thus the only possibilities are that $\hat{\theta}=0$ (which is impossible since $\bar{v} \neq b$ ) or that $\omega(\hat{(} \theta), b)<0$. That is, if $\bar{v}-b>0$, then $C$ contains points at which $\omega$ takes values of opposite signs, which completes the proof of the existence of an equilibrium via the intermediate value theorem.

Proof of Theorem 5.2. The first-order conditions for an efficient allocation with respect to $e, \theta, u$, $g(n)$, and $v(n)$ can respectively be written

$$
\begin{aligned}
0 & =-k+\lambda(0) \\
0 & =\mu\left[f^{\prime}(\theta) u-q^{\prime}(\theta) \sum_{n=0}^{\infty} g(n) v(n)\right]+q^{\prime}(\theta) \sum_{n=0}^{\infty} g(n) v(n)[\lambda(n+1)-\lambda(n)]-f^{\prime}(\theta) u \lambda^{u} \\
r \lambda^{u} & =b+f(\theta)\left[\mu-\lambda^{u}\right] \\
r \lambda(n) & =y(n)-c v(n)+q v(n)[\lambda(n+1)-\lambda(n)-\mu]-\delta\left[\lambda(n)-n \lambda^{u}\right] \\
0 & =q g(n)[\lambda(n+1)-\lambda(n)-\mu]-g(n) c^{\prime}(v(n))
\end{aligned}
$$

where the last equation applies only if $v(n)>0$. Here, as defined in the main text before the statement of the Theorem, $\mu$ is the multiplier on (17), $(\lambda(n))_{n=0}^{\infty}$ are the multipliers on (18), and $\lambda^{u}$ is the multiplier on (19); and I write $\hat{\mu}=\mu-\lambda^{u}$ and $\hat{\lambda}(n)=\lambda(n)-n \lambda^{u}$.

If the equilibrium allocation is efficient, it must be that I can find values of the multipliers $\mu, \lambda^{u}$, and $\{\lambda(n)\}_{n=0}^{\infty}$ so that where $v(\cdot)$ and $\theta$ are the equilibrium vacancy posting strategy and market tightness, equations (55) through (59) are all satisfied. Write $n^{*}$ for the least $n$ such that $v(n)=0$. Rearrange (58) as

$$
(r+\delta) \hat{\lambda}(n)=y(n)-n r \lambda^{u}-c(v(n))+q v(n)[\hat{\lambda}(n+1)-\hat{\lambda}(n)-\hat{\mu}]
$$

and (59) as

$$
c^{\prime}(v(n))=q[\hat{\lambda}(n+1)-\hat{\lambda}(n)-\hat{\mu}] .
$$

Compare (61) with (7) to deduce that if $n<n^{*}$, then

$$
[\hat{\lambda}(n+1)-\hat{\lambda}(n)-\hat{\mu}]=(1-\eta(n))[J(n+1)-J(n)]
$$

while $\hat{\lambda}\left(n^{*}+1\right)-\hat{\lambda}\left(n^{*}\right)-\hat{\mu}<0$.

The next step of the proof is to show that $\lambda^{u}=V^{u}$. To do this, first observe that because $v\left(n^{*}\right)=0$, the first-order condition for the efficient value of $g\left(n^{*}\right)$ takes the simple form

$$
(r+\delta) \lambda\left(n^{*}\right)=y\left(n^{*}\right)-n^{*} r \lambda^{u}
$$


whereas the HJB equation for a firm with $n^{*}$ workers is

$$
(r+\delta) J\left(n^{*}\right)=y\left(n^{*}\right)-n^{*} r V^{u}
$$

It follows that

$$
(r+\delta)\left[\lambda\left(n^{*}\right)-J\left(n^{*}\right)\right]=n^{*} r\left[V^{u}-\lambda^{u}\right] .
$$

Next, write the HJB equation for a firm with $n^{*}-1$ workers as in (51) as

$$
\begin{aligned}
(r+\delta)\left[J\left(n^{*}\right)-J\left(n^{*}-1\right)\right]-c\left(v\left(n^{*}-1\right)\right) & \left.+q v\left(n^{*}-1\right)\left(1-\eta\left(n^{*}-1\right)\right)\left[J\left(n^{*}\right)-J\left(n^{*}-1\right)\right]\right\} \\
& =(r+\delta) J\left(n^{*}\right)-y\left(n^{*}-1\right)+\left(n^{*}-1\right) r V^{u} .
\end{aligned}
$$

and analogously rearrange (60) in the case $n=n^{*}-1$ as

$$
\begin{aligned}
(r+\delta)\left[\hat{\lambda}\left(n^{*}\right)-\hat{\lambda}\left(n^{*}-1\right)\right]-c\left(v\left(n^{*}-1\right)\right) & \left.+q v\left(n^{*}-1\right)\left[\hat{\lambda}\left(n^{*}\right)-\hat{\lambda}\left(n^{*}-1\right)-\hat{\mu}\right]\right\} \\
& =(r+\delta) \hat{\lambda}\left(n^{*}\right)-y\left(n^{*}-1\right)+\left(n^{*}-1\right) \lambda^{u}
\end{aligned}
$$

Subtract (64) from (65) and substitute from (62) and (63) to see that

$$
(r+\delta)\left[\hat{\lambda}\left(n^{*}-1\right)-J\left(n^{*}-1\right)\right]=\left(n^{*}-1\right) r\left[V^{u}-\lambda^{u}\right] .
$$

Continue inductively to establish that for each $n \leq n^{*}$,

$$
(r+\delta)[\hat{\lambda}(n)-J(n)]=n r\left[V^{u}-\lambda^{u}\right]
$$

and then take first differences to establish that whenever $1 \leq n \leq n^{*}$,

$$
[\hat{\lambda}(n)-\hat{\lambda}(n-1)]-[J(n)-J(n-1)]=\frac{r V^{u}-r \lambda^{u}}{r+\delta} .
$$

Compare (66) with (62) to deduce that

$$
\eta(n-1)[J(n)-J(n-1)]=\hat{\mu}-\frac{r V^{u}-r \lambda^{u}}{r+\delta}
$$

which is constant and independent of $n$. The HJB equation for an unemployed worker then implies that

$$
r V^{u}=b+f(\theta) \frac{\sum_{n=0}^{n^{*}-1} g(n) v(n) \eta(n)[J(n+1)-J(n)]}{\sum_{n=0}^{n^{*}-1} g(n) v(n)}
$$

which is a weighted average of equal terms; it follows that

$$
r V^{u}=b+f(\theta)\left[\hat{\mu}-\frac{r V^{u}-r \lambda^{u}}{r+\delta}\right] .
$$

Write (57) as $r \lambda^{u}=b+f(\theta) \hat{\mu}$ and subtract to deduce that

$$
r V^{u}-r \lambda^{u}=-f(\theta) \frac{r V^{u}-r \lambda^{u}}{r+\delta}
$$

so that $V^{u}=\lambda^{u}$.

It now follows immediately from (63) that $\hat{\lambda}(n)=J(n)$ for $n \leq n^{*}$, so that (21) now follows 
immediately from (67).

The converse, that if (21) holds then the equilibrium is constrained efficient, follows immediately from the fact that in this case, the values $J(\cdot)$ and $V^{u}$ solve the first-order conditions for the planner's problem, together with the concavity of that problem.

Proof of Corollary 5.3. Rewrite (56) by multiplying by $\theta$ and substituting for $u$ using the constraint (17) to see that

$$
\hat{\mu}\left[\frac{f^{\prime}(\theta) q(\theta)}{f(\theta)}-q^{\prime}(\theta)\right] \sum_{n=0}^{\infty} g(n) v(n)+q^{\prime}(\theta) \sum_{n=0}^{\infty} g(n) v(n)[\hat{\lambda}(n+1)-\hat{\lambda}(n)]=0 .
$$

Replacing $f(\theta)=\theta q(\theta)$ implies that $f^{\prime}(\theta) q(\theta) / f(\theta)=q(\theta) / \theta+q^{\prime}(\theta)$. Substitute this expression and use (21) to obtain that

$$
\hat{\mu} \frac{q(\theta)}{\theta} \sum_{n=0}^{\infty} g(n) v(n)+q^{\prime}(\theta) \sum_{n=0}^{\infty} g(n) v(n) \frac{\hat{\mu}}{\eta(n)}=0
$$

so that either $\hat{\mu}=0$ (which implies that $\mu=\lambda^{u}$, so that the shadow value of a match is the same as the value of an unemployed worker, which happens only if the economy is not productive enough to generate positive entry) or else (25) holds.

Proof of Proposition 6.1. Consider a steady-state equilibrium allocation. According to Theorem 5.2, efficiency requires that $\hat{\lambda}(n)-\hat{\lambda}(n-1)$ take some constant value $\bar{\lambda}$ for all $1 \leq n \leq n^{*}$. Then (61) implies that

$$
c^{\prime}(v(n))=q[\bar{\lambda}-\hat{\mu}],
$$

so that also $v(n) \equiv \bar{v}$ is constant for $1 \leq n \leq n^{*}$. Rearrange (60) analogously to (65) and substitute that $v(n)$ is constant and $\hat{\lambda}(n)-\hat{\lambda}(n-1)=\bar{\lambda}$ to deduce that

$$
(r+\delta) \bar{\lambda}-c(\bar{v})+q \bar{v}[\bar{\lambda}-\hat{\mu}]\}-(r+\delta) \hat{\lambda}(n)-(n-1) \lambda^{u}=-y(n-1) .
$$

All but one term on the left side of (69) is a constant, and by hypothesis the remaining term is an affine function of $n$, while the right side is strictly convex in $n$. This equation needs to be satisfied whenever $1 \leq n \leq n^{*}$. If $n^{*} \geq 3$, this cannot be true.

If $n^{*}=2$, so that $v(2)=0$ but $v(1)>0$, then the HJB equations defining $\hat{\lambda}(n)$ for $n=0,1,2$ take the form

$$
\begin{aligned}
& (r+\delta) \hat{\lambda}(0)=-c(\bar{v})+q \bar{v}[\bar{\lambda}-\hat{\mu}] \\
& (r+\delta) \hat{\lambda}(1)=y(1)-\lambda^{u}-c(\bar{v})+q \bar{v}[\bar{\lambda}-\hat{\mu}] \\
& (r+\delta) \hat{\lambda}(2)=y(2)-2 \lambda^{u}
\end{aligned}
$$

The multiplier on $e$, equation (55), establishes that $\hat{\lambda}(0)=k$. Taking first differences then proves that

$$
(r+\delta) \bar{\lambda}=(r+\delta)[\hat{\lambda}(1)-\hat{\lambda}(0)]=y(1)-\lambda^{u}
$$

and

$$
(r+\delta) \bar{\lambda}=(r+\delta)[\hat{\lambda}(2)-\hat{\lambda}(1)]=y(2)-y(1)-\lambda^{u}+c(\bar{v})-q \bar{v}[\bar{\lambda}-\hat{\mu}]=y(2)-y(1)-\lambda^{u}-(r+\delta) k
$$


which establishes that $y(2)-2 y(1)=(r+\delta) k$. The left side of this equation is negative since $y(\cdot)$ is strictly concave; the right side is positive.

Finally, if both in the equilibrium and in the efficient allocation only firms with no incumbent workers post vacancies, the Hosios condition is necessary and sufficient for efficiency. Corollary 5.3 establishes necessity. The proof of sufficiency is elementary. Define $\hat{\lambda}(1)=J(1), \hat{\lambda}(0)=J(0)=k$, $\lambda^{u}=V^{u}$, and $\hat{\mu}=\eta[J(1)-J(0)]$, where $\eta$ satisfies the Hosios condition. Then define $\lambda(1)=$ $\hat{\lambda}(1)+\lambda^{u}, \lambda(0)=\hat{\lambda}(0)$, and $\mu=\hat{\mu}+\lambda^{u}$. Then (55) follows from (9), and (57) follows because from (10), $r \lambda^{u}=r V^{u}=b+f(\theta) \eta[J(1)-J(0)]=b+f(\theta) \hat{\mu}$. (58) and (59) are just (6) and (7) rearranged. Finally, to see that (56) holds, multiply by $\theta /[v(0) g(0)]$ and use the consistency condition $\theta u=g(0) v(0)$ to see that it is equivalent to show that $\mu+\theta q^{\prime}(\theta) \lambda(1)-f^{\prime}(\theta) \lambda^{u}=0$.

Proof of Proposition 6.2. According to the first-order condition for vacancy-posting (23), firms in the constrained efficient allocation stop posting vacancies at the smallest size $n_{C E}^{*}$ which satisfies $\hat{\lambda}\left(n_{C E}^{*}+1\right)-\hat{\lambda}\left(n_{C E}^{*}\right)-\hat{\mu} \leq 0$. Using (60), it follows that this is the smallest $n$ such that $\frac{y(n+1)-y(n)-r V^{u}}{r+\delta} \leq \hat{\mu}$. Equivalently, $n_{C E}^{*}$ is the least value satisfying

$$
y\left(n_{C E}^{*}+1\right)-y\left(n_{C E}^{*}\right) \leq r V^{u}+(r+\delta) \hat{\mu} .
$$

The analogous argument using (6) and (7) establishes that under bargaining with commitment, firms stop posting vacancies at the smallest size $n_{C}^{*}$ at which $J\left(n_{C}^{*}+1\right)-J\left(n_{C}^{*}\right) \leq 0$, or equivalently, the smallest value satisfying

$$
y\left(n_{C}^{*}+1\right)-y\left(n_{C}^{*}\right) \leq r V^{u} .
$$

Comparing (70) and (71) establishes the result immediately since $\hat{\mu}>0$.

To see that over-hiring is greater if firms bargaining without commitment as in Acemoglu and Hawkins (2010), it is easiest to consider a continuous-worker version of the model, as in that paper. The analog of $(71)$ in that environment is that $n_{C}^{*}$ is defined by

$$
y^{\prime}\left(n_{C}^{*}\right)=r V^{u}
$$

On the other hand, under bargaining without commitment, the HJB equation for firms takes the form

$$
(r+\delta) J(n)=y(n)-n w(n)-c(v(n))+q v(n) J^{\prime}(n),
$$

where $v(n)$ maximizes the flow gain from posting vacancies, so that $v(n)=0$ if $J^{\prime}(n) \leq 0$, while if $J^{\prime}(n)>0$ then

$$
c^{\prime}(v(n))=q J^{\prime}(n) .
$$

Acemoglu and Hawkins (2010) show (Lemma 1) that in such an environment, the flow wage paid by a firm with $n$ workers to each of its employees depends only on the flow value of an unemployed worker, $V^{u}$, the bargaining power $\eta(n)$ (which I assume constant and equal to $\eta$ ), and the production function of the firm, with

$$
w(n)=(1-\eta) r V^{u}+n^{-\frac{1}{\eta}} \int_{0}^{n} \nu^{\frac{1-\eta}{\eta}} y^{\prime}(\nu) d \nu .
$$

It follows in this environment that firms stop posting vacancies at that firm size at which $J^{\prime}\left(n_{N C}^{*}\right)=$ 0 , or equivalently, when $\frac{d}{d n}[y(n)-n w(n)]=0$. Using the functional form for wages from (73), it follows that

$$
\frac{1-\eta}{\eta} n_{N C}^{*}{ }^{-\frac{1}{\eta}} \int_{0}^{n_{N C}^{*}} \nu^{\frac{1}{\eta}-1} y^{\prime}(\nu) d \nu-(1-\eta) r V^{u}=0
$$


or equivalently,

$$
\frac{\int_{0}^{n_{N C}^{*}} \nu^{\frac{1}{\eta}-1} y^{\prime}(\nu) d \nu}{\int_{0}^{n_{N C}^{*}} \nu^{\frac{1}{\eta}-1} d \nu}=r V^{u} .
$$

The term on the left side of (74) is a weighted average of $y^{\prime}(\nu)$ for $\nu \in\left[0, n_{N C}^{*}\right]$; since $y(\cdot)$ is strictly concave, this is strictly greater than $y^{\prime}\left(n_{N C}^{*}\right)$. The left side of (74) is decreasing in $n_{N C}^{*}$. Comparing (72) and (74) then establishes that $n_{N C}^{*}>n_{C C}^{*}$.

Proof of Proposition 6.3. Immediate from the argument given in the proof of Proposition 6.2, together with the observation that $r V^{u}$ falls in general equilibrium under bargaining with commitment since welfare must be lower in a constrained inefficient allocation.

Proof of Proposition 8.2. I show first that the value of $V^{u}$ characterizes the firm's value function completely, and then that there is a unique value of $V^{u}$ that is consistent with the free entry condition.

First, note that the maximal size of firms is the largest value of $n^{*}$ such that $y\left(n^{*}\right)-y\left(n^{*}-1\right) \geq$ $r V^{u}$. Firms with $n^{*}$ workers do not hire further workers according to (30), so that (27) implies that $(r+\delta) J\left(n^{*}\right)=y\left(n^{*}\right)-n^{*} r V^{u}$.

Next, the indifference condition for an unemployed worker deciding which submarket to search, equation (29), together with the bargaining equation (4), establishes that for $n<n^{*}$,

$$
f(n)=\frac{r V^{u}-b}{\eta(n)[J(n+1)-J(n)]}
$$

The assumptions on the matching function establish that there is a function $\chi:(0, \infty) \rightarrow(0, \infty)$ defined by $\chi(f(\theta))=q(\theta)$ for all $\theta$, and that this function is strictly decreasing. (If the matching function is Cobb-Douglas, with $q(\theta)=Z \theta^{-\psi}$, then $\chi(f)=Z^{\frac{1}{1-\psi}} f^{-\frac{\psi}{1-\psi}}$.) Write (27) as

$(r+\delta) J(n)=y(n)-n r V^{u}+\max _{v}\left[-c(v)+(1-\eta(n)) \chi\left(\frac{r V^{u}-b}{\eta(n)[J(n+1)-J(n)]}\right) v[J(n+1)-J(n)]\right]$.

Using an envelope theorem argument, it is clear that (75) can be solved uniquely for $J(n)$, conditional on the value of $J(n+1)$ and the value of $r V^{u}$, since the left side is increasing in $J(n)$ and the right side is decreasing in $J(n)$. Moreover, the resulting value of $J(n)$ is a continuous and strictly decreasing function of $V^{u}$ (both directly and via the effect on $\chi(\cdot)$ ), and a continuous and strictly increasing function of $J(n+1)$. Thus, the value of $J(n)$ for $n=0,1, \ldots, n^{*}$ is uniquely determined given $r V^{u}$. Moreover, since $J\left(n^{*}\right)$ is decreasing in $V^{u}$, and $J(n)$ is decreasing in $V^{u}$ conditional on $J(n+1)$ for each $n$, it follows by induction that the resulting value of $J(0)$ is also continuously and strictly decreasing in $V^{u}$. (A full proof of this argument requires being careful about what happens at those values of $V^{u}$ such that $y(n)-y(n-1)=r V^{u}$ exactly for some $n>0$. Let $\hat{V}^{u}$ denote such a value of $V^{u}$, and let $\hat{n}^{*}$ be the value of $n$ such that $y\left(\hat{n}^{*}\right)-y\left(\hat{n}^{*}-1\right)=r \hat{V}^{u}$. For $V^{u}=\hat{V}^{u}+\varepsilon$, with $\varepsilon>0$ sufficiently small, firms stop hiring when they have $n^{*}=\hat{n}^{*}-1$ workers, while for $V^{u}=\hat{V}^{u}-\varepsilon$ with $\varepsilon<0$ sufficiently small, firms stop hiring when they have $n^{*}=\hat{n}^{*}$ workers. However, it is clear from (75) that the value of $J\left(\hat{n}^{*}-1\right)$ changes continuously in $V^{u}$ in this neighborhood, since the gain associated with hiring the $\hat{n}^{*}$ th worker is small when $V^{u}=\hat{V}^{u}-\varepsilon$, and in addition firms with $\hat{n}^{*}-1$ workers only match slowly. Since the argument is intuitive, I omit the more formal details.)

Finally, if $V^{u}$ is sufficiently close to $b$, it is clear that $J(0)>k$ since firms can hire workers very rapidly and need to pay them only a small hiring bonus; on the other hand, as $V^{u} \rightarrow+\infty$, 
$J(0) \rightarrow 0$. The intermediate value theorem then implies that a value of $V^{u}$ exists such that the free entry condition (9) is satisfied, and this value is unique because $J(0)$ is strictly decreasing in $V^{u}$. Given $V^{u}$, constructing the rest of the equilibrium is straightforward. The value of firms $J(\cdot)$ was already detailed. Hiring bonuses are then defined according to (4) and the matching rates of workers in each submarket follow from (29). The optimal vacancy-posting policies of firms can be constructed as the solution to (28), and this allows the firm size distribution to be constructed inductively, so that for each $n=0,1, \ldots, n^{*}, g\left(n^{*}\right)$ is a known multiple of the entry rate $e$. Since market tightness in each submarket is known, (34) allows the number of unemployed workers searching each submarket to be determined, and then (33) allows the determination of $e$.

Proof of Theorem 8.3. To establish efficiency, I need to characterize the constrained efficient allocation. As noted in the main text, this differs from the constrained efficient allocation under random search because of the different search technology. Under directed search, the planner chooses an unemployment rate $u$, an entry rate $e$, a maximum firm size $n^{*}$ and a firm size distribution $g(0), g(1), \ldots, g\left(n^{*}\right)$, an allocation of unemployed workers to submarkets $u(0), u(1), \ldots, u\left(n^{*}-1\right)$, a sequence of market tightnesses $\theta(0), \theta(1), \ldots, \theta\left(n^{*}-1\right)$, and a sequence of vacancy-posting policies for firms $v(0), v(1), \ldots, v\left(n^{*}-1\right), v\left(n^{*}\right)=0$ so as to solve

$$
\max \int_{0}^{\infty} e^{-r t}\left[b u-e k+\sum_{n=0}^{n^{*}} g(n)[y(n)-c(v(n))]\right] d t
$$

subject to the constraints (31) through (35). Rewrite (34) by multiplying by $q(\theta(n))$, so that it takes the form

$$
f(\theta(n)) u(n)-q(\theta(n)) g(n) v(n)=0
$$

Denote the multiplier on (31) by $\lambda(0)$, on (32) by $\lambda(n)$, on (33) by $\chi$, on (76) by $\mu(n)$, and on (35) by $\lambda^{u}$. Define $\hat{\lambda}(n)=\lambda(n)-n \lambda^{u}$, and $\hat{\mu}(n)=\mu(n)-\lambda^{u}$. Then, taking into account that the firm size distribution and the (aggregate) unemployment rate are predetermined, the first-order conditions for a constrained efficient allocation can be written

$$
\begin{aligned}
{[g(n)] } & (r+\delta) \hat{\lambda}(n) & =y(n)-n r \lambda^{u}-c(v(n))+q(\theta(n)) v(n)[\hat{\lambda}(n+1)-\hat{\lambda}(n)-\hat{\mu}(n)] \\
{[v(n)] } & c^{\prime}(v(n)) & =q(\theta(n))[\hat{\lambda}(n+1)-\hat{\lambda}(n)-\hat{\mu}(n)] \\
{[e] } & \hat{\lambda}(0) & =k \\
{[u] } & r \lambda^{u} & =b+\chi \\
{[u(n)] } & \chi & =\hat{\mu}(n) f(\theta(n)) \\
{[\theta(n)] } & 0 & =q^{\prime}(\theta(n)) g(n) v(n)[\hat{\lambda}(n+1)-\hat{\lambda}(n)-\hat{\mu}(n)]+f^{\prime}(\theta(n)) u(n) \hat{\mu}(n)
\end{aligned}
$$

Simplify (82) using the observation that $f^{\prime}(\theta)=\theta q^{\prime}(\theta)+q(\theta)$ and rearrange to obtain the equivalent form

$$
\hat{\mu}(n)=-\frac{\theta(n) q^{\prime}(\theta(n))}{q(\theta(n))}[\hat{\lambda}(n+1)-\hat{\lambda}(n)] .
$$

Substitute from (83) and compare (77) with (27), (78) with (28), (79) with (9), and (80) and (81) with (29). It is apparent that the unique equilibrium allocation satisfies the first-order conditions for a constrained efficient allocation with $J(n)=\hat{\lambda}(n)$ and $V^{u}=\lambda^{u}$ if and only if $\frac{\theta(n) q^{\prime}(\theta(n))}{q(\theta(n))}=\eta(n)$ for all $n=0,1, \ldots, n^{*}$. Because the planner's problem is concave, the first-order conditions for optimality are necessary and sufficient, completing the proof. 
Proof of Proposition 9.2. I first show that in equilibrium, $n^{*}$ satisfies (44). To show this, first rearrange (41) as

$$
n^{*} r V^{u}=y\left(n^{*}\right)-n^{*} \frac{r+\delta}{1-\eta} \frac{\gamma}{q(\theta)}-(r+\delta) k .
$$

Multiply (40) by $(r+\delta) n^{*}$ to show that,

$$
n^{*} y\left(n^{*}\right)-n^{*} y\left(n^{*}-1\right)-n^{*} r V^{u}>n^{*} \frac{r+\delta}{1-\eta} \frac{\gamma}{q(\theta)} \geq n^{*} y\left(n^{*}+1\right)-n^{*} y\left(n^{*}\right)-n^{*} r V^{u},
$$

then substitute from (84) to show that

$$
\left(n^{*}-1\right) y\left(n^{*}\right)-n^{*} y\left(n^{*}-1\right)>-(r+\delta) k \geq n^{*} y\left(n^{*}+1\right)-\left(n^{*}+1\right) y\left(n^{*}\right) .
$$

Rearranging (85) shows that

$$
\frac{1}{n^{*}}\left[y\left(n^{*}\right)-(r+\delta) k\right] \geq \frac{1}{n^{*}+1}\left[y\left(n^{*}+1\right)-(r+\delta) k\right],
$$

and, if $n^{*} \geq 2$,

$$
\frac{1}{n^{*}}\left[y\left(n^{*}\right)-(r+\delta) k\right]>\frac{1}{n^{*}-1}\left[y\left(n^{*}-1\right)-(r+\delta) k\right]
$$

which completes the proof of the claim since $y(\cdot)$ is strictly concave. I can therefore write $X=$ $\frac{1}{n^{*}}\left[y\left(n^{*}\right)-(r+\delta) k\right]$ independently of $\theta$ and $V^{u}$. Note that $X>b$ according to (2). Also note that $n^{*}$ is generically unique.

To complete the proof of the Proposition, rewrite the free-entry condition (41) as

$$
r V^{u}=X-\frac{r+\delta}{1-\eta} \frac{\gamma}{q(\theta)}
$$

The first term on the right side of (86) was just shown to be constant and independent of $\theta$ and $V^{u}$; thus the right side of (86) defines a continuous, strictly decreasing function of $\theta$ which takes the value $X$ when $\theta \rightarrow 0$ and diverges to $-\infty$ as $\theta \rightarrow+\infty$. By contrast, the right side of the HJB equation for the unemployed worker, (42), defines $r V^{u}$ as a continuous, strictly increasing function of $\theta$, and takes the value $b$ when $\theta=0$ and diverges to $+\infty$ as $\theta \rightarrow+\infty$. Because $X>b$, it follows by the intermediate value theorem that there is a unique pair $\left(\theta, V^{u}\right)$ satisfying (41) and (42). Construction of the remainder of the equilibrium given the value of $\theta$ and $V^{u}$ is routine: (14) determines the unemployment rate $u$, and (43) then determines the flow entry rate $e$ in the generic case where $n^{*}$ is uniquely determined. ${ }^{18}$

Proof of Proposition 9.3. Eliminate $e$ from the planner's problem using constraint (43) to see that the constrained efficient allocation solves

$$
\max _{n^{*}, \theta, u} \int_{0}^{\infty} e^{-r t}\left[\left(\frac{1}{n^{*}(r+\delta)}\left[y\left(n^{*}\right)-(r+\delta) k\right]\right) f(\theta) u-\gamma \theta u+b u\right] d t
$$

subject to $\dot{u}=\delta(1-u)-\theta q(\theta) u$. It is immediate that the constrained efficient choice of $n^{*}$ solves (44), so coincides with its equilibrium value.

\footnotetext{
${ }^{18}$ In the non-generic case when two values, $n^{*}$ and $n^{*}+1$, yield the same value for $\frac{1}{n}[y(n)-(r+\delta) k]$, then there are multiple equilibria according to the proportion of firms with target size $n^{*}$ and the proportion with target size $n^{*}+1$, and these equilibria differ in the entry rate $e$, but all such equilibria are associated with the same values for the key endogenous variables $\theta$ and $V^{u}$.
} 
Proof of Proposition 9.4. As in the proof of Proposition 9.2, write $X=\frac{1}{n^{*}}\left[y\left(n^{*}\right)-(r+\delta) k\right]$ where $n^{*}$ satisfies (44). Denote by $\lambda$ the Lagrange multiplier on the law of motion for unemployment. Then, using the formulation in (87), the first-order conditions for the constrained efficient choice of $\theta$ and $V^{u}$ can be written: ${ }^{19}$

$$
\begin{aligned}
& {[u] \quad r \lambda=b-\gamma \theta+f(\theta) \frac{X}{r+\delta}-(\delta+f(\theta)) \lambda} \\
& {[\theta] \quad 0=f^{\prime}(\theta) u \frac{X}{r+\delta}-\gamma u-\lambda f^{\prime}(\theta) u \text {. }}
\end{aligned}
$$

Eliminate $\lambda$ using (88), substitute into (89), and rearrange to see that

$$
\frac{X-b}{\gamma}=\frac{r+\delta+f(\theta)-\theta f^{\prime}(\theta)}{f^{\prime}(\theta)}
$$

On the other hand, rewrite the equilibrium free-entry condition (41) as

$$
\frac{X-r V^{u}}{\gamma}=\frac{r+\delta}{1-\eta} \frac{1}{q(\theta)}
$$

and substitute from (42) to establish that in equilibrium

$$
\frac{X-b}{\gamma}=\frac{r+\delta+\eta f(\theta)}{(1-\eta) q(\theta)} .
$$

Comparison of (90) and (91) shows that a necessary and sufficient condition for the equilibrium allocation to be efficient is that the right sides of these two equations should coincide. To complete the proof, first suppose that (47) is satisfied at the equilibrium allocation. It is immediate from (47) that $\eta f(\theta)=-\theta^{2} q^{\prime}(\theta)=f(\theta)-\theta f^{\prime}(\theta)$ and $(1-\eta) q(\theta)=q(\theta)+\theta q^{\prime}(\theta)=f^{\prime}(\theta)$, so that the right sides of (90) and (91) coincide. Conversely, suppose that the equilibrium allocation is constrained efficient, so that the equilibrium market tightness equals the constrained efficient value. Equate the right sides of $(90)$ and $(91)$, cross-multiply by $\left.(1-\eta) q(\theta) f^{\prime}(\theta)\right)$, and use that $f(\theta)=\theta q(\theta)$ to deduce that

$$
(r+\delta+\theta q(\theta))\left(\eta q(\theta)+\theta q^{\prime}(\theta)\right)=0 .
$$

Since $\theta q(\theta)=f(\theta) \geq 0$ and $r+\delta>0$, it follows that $\eta q(\theta)+\theta q^{\prime}(\theta)=0$, which is the claimed condition (47).

\section{References}

Acemoglu, Daron, and Robert Shimer. 1999. "Holdups and Efficiency with Search Frictions." International Economic Review, 40(4): 827-49.

\footnotetext{
${ }^{19}$ These first-order conditions are intuitive. The first-order condition for $u$ relates the marginal benefit of having more unemployed workers (that it increases the rate of firm entry consistent with labor market tightness and target firm size, $e=\theta q(\theta) u / n^{*}=f(\theta) u / n^{*}$, and that it generates additional unemployment income) with the costs (that it reduces the number of unemployed in future via increased matching, and also since fewer employed workers today mean less firm destruction, also leading to lower unemployment in future). The first-order condition for $\theta$ requires that the gains from a tighter labor market (that greater entry is feasible, ceteris paribus, and that vacancy posting is cheaper - note that $-d \frac{1}{q(\theta)} / d \theta>0$ ) equal the costs (that more unemployed workers will find jobs, reducing unemployment).
} 
Acemoglu, Daron, and William B. Hawkins. 2010. "Wages and Employment Persistence with Multi-worker Firms." Unpublished.

Bauer, Christian, and Jörg Lingens. 2010. "Does Collective Wage Bargaining Restore Efficiency in a Search Model with Large Firms?" Unpublished.

Brown, Charles, and James Medoff. 1989. "The Employer Size-Wage Effect." Journal of Political Economy, 97(5): 1027-1059.

Brown, Charles, and James Medoff. 2003. "Firm Age and Wages." Journal of Labor Economics, 21(3): 677-697.

Cahuc, Pierre, and Etienne Wasmer. 2001. "Labour Market Efficiency, Wages and Employment when Search Frictions Interact with Intrafirm Bargaining." Center for Economic Policy Research Discussion Paper 2812, London.

Cahuc, Pierre, Francois Marque, and Etienne Wasmer. 2008. "A Theory of Wages and Labor Demand with Intra-Firm Bargaining and Matching Frictions." International Economic Review, 49(3): 943-972.

Coşar, A. Kerem, Nezih Guner, and James Tybout. 2010. "Firm Dynamics, Job Turnover, and Wage Distributions in an Open Economy." National Bureau of Economic Research Working Paper 16326, Cambridge, MA.

Davis, Steven J., and John C. Haltiwanger. 1991. "Wage Dispersion between and within U.S. Manufacturing Plants, 1963-86." Brookings Papers on Economic Activity: Microeconomics, $115-200$.

Davis, Steven J., John C. Haltiwanger, Ron Jarmin, and Javier Miranda. 2006. "Volatility and Dispersion in Business Growth Rates: Publicly Traded versus Privately Held Firms." 2006 NBER Macroannual.

Davis, Steven J., R. Jason Faberman, and John C. Haltiwanger. 2010. "The Establishment-Level Behavior of Vacancies and Hiring." National Bureau of Economic Research Working Paper 16265.

Delacroix, Alain, and Roberto M. Samaniego. 2009. "Joint Determination of Product and Labor Market Policies in a Model of Rent Creation and Division." Unpublished.

Ebell, Monique, and Christian Haefke. 2009. "Product Market Deregulation and the U.S. Employment Miracle." Review of Economic Dynamics, 12(3): 479-504.

Elsby, Michael, and Ryan Michaels. 2010. "Marginal Jobs, Heterogeneous Firms, and Unemployment Flows." unpublished, available at http://www-personal.umich.edu/ elsby/ rev-Jan-2010.pdf.

Felbermayr, Gabriel, and Julien Prat. 2007. "Product Market Regulation, Firm Selection and Unemployment." Institute for the Study of Labor (IZA) Discussion Paper 2754.

Hawkins, William B. 2006. "Competitive Search, Efficiency, and Multi-worker Firms." Ph.D. diss., MIT, Chapter 1.

Hawkins, William B. 2011. "Identifying the Nature of Bargaining between Workers and Large Firms." in prep. 
Helpman, Elhanan, and Oleg Itskhoki. 2010. "Labour Market Rigidities, Trade and Unemployment." Review of Economic Studies, 77(3): 1100-1137.

Hosios, Arthur J. 1990. "On the Efficiency of Matching and Related Models of Search and Unemployment." Review of Economic Studies, 57(2): 279-298.

Kaas, Leo, and Philipp Kircher. 2010. "Efficient Firm Dynamics in a Frictional Labor Market." unpublished, available at http://personal.lse.ac.uk/kircher/Papers/ Efficient-Firm-Dynamics-in-a-Frictional-Labor-Market.pdf.

Lester, Benjamin. 2010. "Directed search with multi-vacancy firms." Journal of Economic Theory, 145(6): 2108-2132.

Lucas, Robert E. 1978. "On the Size Distribution of Business Firms." Bell Journal of Economics, 9(2): 508-523.

Moen, Espen R. 1997. "Competitive Search Equilibrium." Journal of Political Economy, 105(2): 385-411.

Mortensen, Dale T. 2009. "Wage Dispersion in the Search and Matching Model with Intra-Firm Bargaining." National Bureau of Economic Research Working Paper 15033, Cambridge, MA.

Petrongolo, Barbara, and Christopher A. Pissarides. 2001. "Looking into the Black Box: A Survey of the Matching Function." Journal of Economic Literature, 39(2): 390-431.

Roys, Nicolas. 2010. "Estimating Labor Market Rigidities with Heterogeneous Firms." unpublished, Paris School of Economics and CEMMAP.

Shimer, Robert. 1996. "Contracts in a Frictional Labor Market." PhD diss. MIT, Chapter 1.

Shimer, Robert. 2005. "The Cyclical Behavior of Equilibrium Unemployment and Vacancies." American Economic Review, 95(1): 25-49.

Smith, Eric. 1999. "Search, Concave Production and Optimal Firm Size." Review of Economic Dynamics, 2(2): 456-471.

Stole, Lars A., and Jeffrey Zwiebel. 1996a. "Intra-firm Bargaining under Non-binding Contracts." Review of Economic Studies, 63(3): 375-410.

Stole, Lars A., and Jeffrey Zwiebel. 1996b. "Organizational Design and Technology Choice under Intrafirm Bargaining." American Economic Review, 86(1): 195-222.

Tan, Serene. 2010. "Directed Search and Firm Size." unpublished, available at http://serene. tan.economics.googlepages.com/firmsize.pdf.

van Ours, Jan, and Geert Ridder. 1992. "Vacancies and the Recruitment of New Employees." Journal of Labor Economics, 10(2): 138-155.

Wolinsky, Asher. 2000. "A Theory of the Firm with Non-Binding Employment Contracts." Econometrica, 68(4): 875-910. 